\title{
LAS ALTERACIONES FORMALES EN EL DIBUJO ANIMADO
}

Por:

Nathaly Ortiz Lugo

Diseñadora gráfica

Universidad del Valle

natorlug@gmail.com

Andrés Reina Gutiérrez

Profesor del Departamento de Diseño

Universidad del Valle

salomonreina@gmail.com

\section{Resumen:}

El presente artículo se deriva del capítulo introductorio de la investigación: "Alteraciones formales en gestos y comportamientos del personaje de dibujos animados"', y surge de la preocupación por estudiar el desempeño y la finalidad de los cambios formales en los personajes del dibujo animado, como uno de sus recursos narrativos fundamentales. La noción de alteración está referida aquí a aquellas "transformaciones no permanentes" que afectan de manera exagerada la estructura del personaje mediante diferentes modos de composición y representación tanto de la imagen como del movimiento; aunque es necesario enfatizar que las alteraciones son transformaciones, es decir, mutaciones formales, que se efectúan propiamente en la imagen estática y producen así diferentes niveles de ilusión de movimiento.

Palabras claves: dibujos animados, imagen en movimiento alteración formal, representación, acción.

\begin{abstract}
:
This article comes from the introductory chapter of the investigation "formal alterations in gestures and behavior of cartoon character", and arises from the preoccupation about studying the performance and the aim of the formal changes in the cartoon characters as one of the main narrative resource. The concept of alteration is referred to those "non permanent transformations", that influences in an exaggerated way the character's structure through different composition and representation modes as much of the image as of the movement.
\end{abstract}

Key words: cartoons, motion picture, formal alterations, representation, action. 


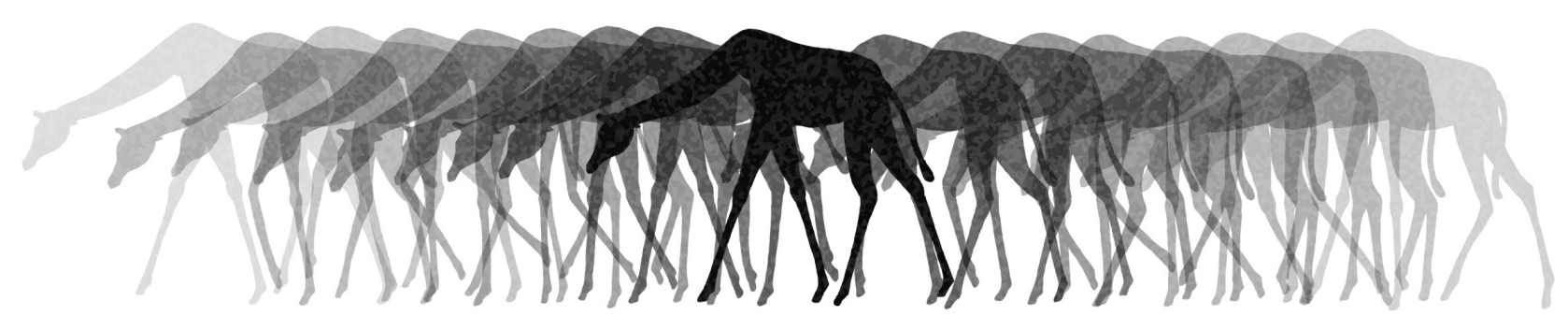

\section{Introducción}

Para poder identificar las transformaciones formales en los personajes de dibujos animados, empleadas para representar algunas expresiones de movimiento, se deben estudiar inicialmente los elementos del contexto dramatúrgico que configuran determinados significados, según las categorías de relato animado. En este estudio tomaremos como marco referencial las manifestaciones de los primeros años de la animación (de 1910 a 1950), según el período, debido a las influencias y técnicas empleadas, que pueden apreciarse aún en los relatos animados contemporáneos. El estudio de estos elementos permitirá identificar algunas alteraciones por medio de patrones de composición en el dibujo animado como recursos claves de comunicación de acciones narrativas afines a ciertas figuras de retórica; es decir, la alteración como modo de expresión formal, para acentuar significados de expresión estilística al servicio del relato.

La animación es un medio de expresión que permite representar el movimiento y, de esta manera, simular la vida de los elementos inanimados. Su desarrollo y perdurabilidad en el tiempo se deben a los intereses científicos que en un principio fueron explorados para la consolidación de su discurso, que junto al cine y la fotografía evolucionaron con mucha cercanía. Según la Asociación Internacional del Cine de Animación (ASIFA), la animación es toda creación realizada imagen por imagen (diferente a la creación de imágenes de registro automático como en el cine), en la cual se hacen presentes diversos instrumentos y técnicas que permiten su realización, pero cuyos hechos o ejecución del movimiento sólo tienen lugar, por primera vez, cuando son proyectados o reproducidos en la pantalla (Rodríguez B., 2007). En su inicio, la animación se dio a conocer mediante el dibujo de caricaturistas de la época que experimentaban con la incursión al nuevo medio, en compañía con la fotografía que ya venía desarrollando los mecanismos para producir la ilusión del movimiento cinematográfico. De tal modo, que la animación como medio de expresión narrativa, superó rápidamente la instancia de desarrollo técnico, supremamente afín a la del cine, y constituyó su propio discurso (Williams, 2001). Así pues, se conformaron industrias de producción animada como los estudios Fleischer, Disney, Famous, entre otros, que popularizaron el ejercicio del dibujo animado, y lo convirtieron en una de las primeras técnicas gráficas bi-dimensionales que formalizó la imagen en movimiento realizada cuadro a cuadro. El desarrollo de la técnica, fue enriquecido por los fundamentos de un discurso, como el planteamiento de los "doce principios" de Walt Disney: un listado de atributos que debían ser empleados para garantizar que la animación fuera apropiadamente expresiva, fluida y coherente, además que permitiera el trabajo en equipo. Pronto, estos principios serían adoptados por otros estudios de animación y validados como recursos eficaces para producir la ilusión de movimiento real de objetos, animales y humanos, así como de ciertos elementos relacionados con el montaje y otros códigos propios del cine. La consolidación de estos principios fue un resultado de experimentación y ensayo-error que conformó una serie de criterios que siguen prevaleciendo en la actualidad, cuyo propósito incluye, además, configurar el atractivo de personajes tanto en su aspecto físico como sicológico. 
Algunos de estos principios, hacen parte de los elementos compositivos y de montaje de la obra animada, pero otros se efectúa sobre la fisonomía del personaje como por ejemplo, el estirar y encoger ${ }^{2}$, cuyo personaje es transformado por un período corto de tiempo descrito generalmente como "take" (cambio de posición repentino de la figura animada según Johnston \& Thomas, [1981]). Esta distinción permite establecer una de las características de la alteración, en cuanto al movimiento utilizado como modelo de referencia. Dichas transformaciones son denominadas aquí como alteraciones formales debido a que son cambios que condicionan la forma y estructura del personaje de modo permanente o súbito en la obra animada.

Con base en este marco de conceptos, abordaremos, entonces, una revisión sobre la manera como se relaciona la alteración formal de la figura animada y la representación del movimiento corporal en los dibujos animados.

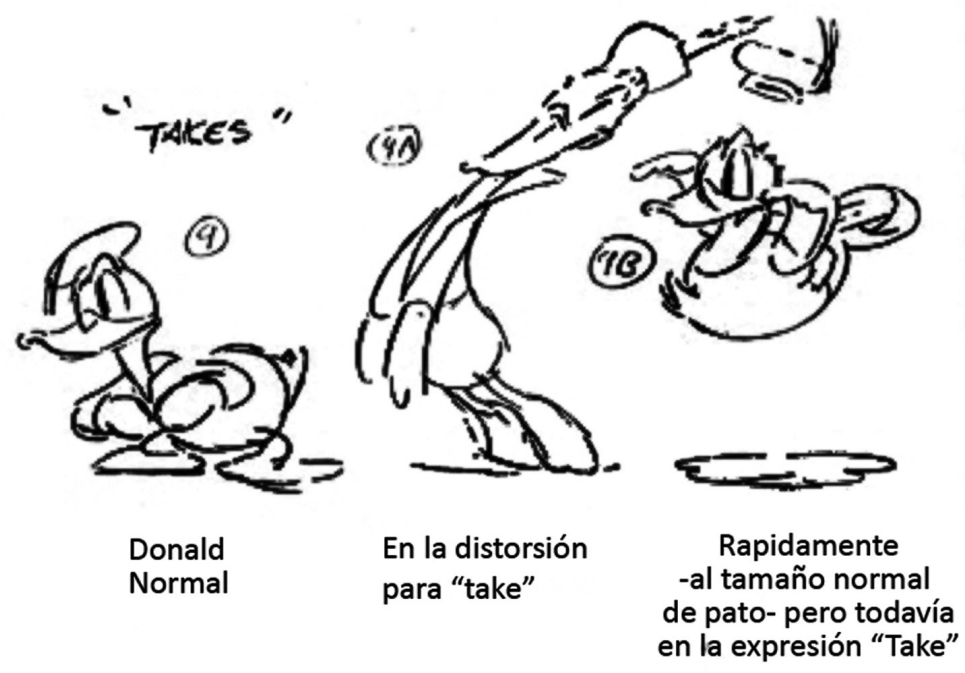

Figura $\mathbf{N}^{\mathbf{0}}$ 1. Ejemplo de Alteración formal al Estirar y encoger. Johnston, Oliver Martin; Thomas, Frank. The Illusion of Life, Disney Animation. New York: Abbeville Press, 1981.

La consolidación de estos principios fue un resultado de experimentación y ensayo-error que conformó una serie de criterios que siguen prevaleciendo en la actualidad, cuyo propósito incluye, además, configurar el atractivo de personajes tanto en su aspecto físico como sicológico. Algunos de estos principios, por ejemplo, el estirar y encoger (donde el personaje es transformado por un período corto), no se efectúan necesariamente sobre la fisonomía del personaje, sino que se emplean en elementos compositivos o de montaje, como el caso del "take" (cambio de posición repentino de la figura animada según Johnston \& Thomas, [1981]). Esta distinción permite establecer una de las características de la alteración, en cuanto al movimiento utilizado como modelo. Dichas transformaciones son denominadas aquí como alteraciones formales debido a que son cambios que condicionan la forma y estructura del personaje de modo permanente o súbito en la obra animada.

Con base en este marco de conceptos, abordaremos, entonces, una revisión sobre la manera como se relaciona la alteración formal de la figura animada y la representación del movimiento corporal en los dibujos animados. 


\section{El dibujo animado}

Denominado cartoon en Estados Unidos, el dibujo animado es una forma de representación clásica en animación y es considerado como una "técnica gráfica plana” (Falcone, 2002), en la cual prevalece la planeación y creación del movimiento del personaje cuadro por cuadro y cuya aplicación manual o dibujada a mano se realiza sobre una superficie llana, por ejemplo, un tablero, un acetato, una película, una tela, un papel o una pared, entre otras superficies. En cuanto a la parte discursiva, Leslie Bishko (2007) ha designado "cartoon style" a las características más sobresalientes del dibujo animado, tales como elementos cómicos o gags, contextos dramáticos, situaciones paradójicas y ha manifestado los 12 principios de animación.

Ambas son categorías fundamentales del dibujo animado; la primera, como determinante técnico del soporte, correspondiente al formato que ha sido empleado durante todo un siglo por los grandes estudios de animación, y la segunda, como la representación de acciones narrativas, que tiene en cuenta los cambios de la figura. En esta aproximación se excluyen los video-clips animados y la animación experimental, por encontrarse fuera del género dramático, en el cual prevalece la unidad narrativa de los personajes y sus contextos de actuación.

Así pues, se puede distinguir una propiedad general del dibujo animado y que trasciende en él: la recurrencia a lo imposible, a la alternatividad de lo no existente y por lo tanto a la exageración y la alteración formal de la representación. La imagen representada puede constituir un imposible verosímil ${ }^{3}$, ya sea por la unión de cualidades disímiles en la realidad (un caballo con alas, una lámpara con actitudes humanas), los efectos inevitables propios de ciertas imágenes (las ilustraciones conflictivas de Escher y en general las composiciones ilusorias) o, sencillamente, las que aparentan copiar la realidad con verosimilitud (como las imágenes fotográficas o las ilustraciones altamente figurativas). De la misma manera, el dibujo animado, al complementar la representación gráfica con la ilusión de movimiento, permite explorar el infinito terreno de lo imaginable.
Para observar las alteraciones formales dadas en el personaje de dibujos animados, se deben revisar algunos de los elementos generales que lo conforman, propensos a modificarse y que producen interpretaciones psicológicas determinadas por la finalidad de la expresión dramática. Con base en estos elementos formales, se inicia la constitución primigenia del personaje, primero, desde la hoja de creación del personaje, comúnmente llamada caracther sheet, en la cual se establece la proporción y escala con respecto a otros personajes, y segundo, en la obra animada propiamente dicha, en cuya historia se introduce o permanece, permitiendo contrastar los cambios drásticos formales que se desarrollan durante las acciones. Estas bases morfológicas son lo que Román Gubern (1992) denomina codificaciones perceptivas o técnicas, que permean otras codificaciones de representación. Nos referimos a los elementos de la representación gráfica que se han constituido en la humanidad por más de 12.000 años. Aunque no los abordaremos en profundidad, mencionaremos los siguientes: el punto, la línea, el plano, el valor, el color, la profundidad, la perspectiva y el movimiento. Con base en estos elementos, la representación gráfica de una imagen puede producir sensaciones de realismo, creando ilusiones perceptivas de formas con profundidad, tridimensionalidad y en general, formas con diversos grados de parecido o iconicidad con el referente, que procuran los ya mencionados imposibles verosímiles. Los personajes animados pueden ser, desde la perspectiva de la codificación icónica, muy semejantes a los seres humanos y a los animales, o, por el contrario, tener sólo un leve parecido que pueda percatarse en objetos o animales humanizados o en humanos deshumanizados; como el caso de la caricatura, que abordaremos más adelante.

La codificación perceptiva o técnica de la representación gráfica es la base de la representación material que permite la imagen percibida. Este procedimiento de materialización, que se produce con la transformación de la sustancia (tinta, papel o pantalla) produce los estímulos que el cerebro traduce en formas mentales, y constituye la base del resto de las codificaciones visuales. 
Codificación icónica: cuyo indicador es el nivel de parecido entre lo representado y los diversos referentes de la realidad. Un hombre, un animal, un objeto o incluso, otras representaciones, como Papá Noel o un genio maravilloso. Cuando el parecido es nulo, la figura ingresa al mundo de la abstracción formal.

Codificación iconográfica: cuya base es la temática de la representación; los elementos de la escena. Este criterio tomado de las categorías de análisis visuales de Panofsky, revela los aspectos de contexto: vestuario, escenografía, utilería y las diversas acciones que puedan referir a contextos de tiempo o lugar, entre otros. Por ejemplo, el pato Donald en acciones cotidianas contemporáneas o el príncipe Felipe, sobre su corcel, enfrentando un gigantesco y maléfico dragón.

Codificación iconológica, también proveniente de las categorías de análisis de Panofsky, presenta indicios de interpretación simbólica o de significado connotado. Por ejemplo, la rosa en La Bella y la Bestia, que aparece también en la versión original, se identifica con claridad como un elemento de relevancia simbólica, es decir, indica la pertinencia de la interpretación (Todorov, 1971) y exige que se indaguen los elementos internos del relato y también los elementos externos. En este caso concreto, algunos consideran que la rosa alude a la sexualidad, otros, al amor.

Codificación estética: está fundamentada por los atributos centrales de la codificación técnica en relación con un contexto cultural determinado. Como en las tendencias artísticas se dio el modo de uso del punto (impresionismo), la línea (renacimiento), el movimiento (el futurismo), etc. Es propiamente lo que se denomina estilo; como lo que diferencia la modalidad de expresión formal de personajes semejantes, bajo distintas formas de representación. Tal es el caso de las diferencias estilísticas entre Disney y Warner, respectivamente por ejemplo en la utilización de fondos y personajes elaborados en comparación a la reutilización y simpleza de los personajes, lo cual también vincularía el modo y tipo de animación ${ }^{4}$, que permitiría encontrar en el movimiento diferencias de estilo.

Codificación retórica, cuyas exploraciones se basan en las formas, acciones y significados representados, según las figuras de la retórica o tropos desarrolladas por Aristóteles. Formas y acciones exageradas, por ejemplo, corresponden a la hipérbole o imágenes que presentan algún tipo de contigüidad, a la metonimia. Las figuras retóricas están implícitamente en casi toda forma de representación, porque la imagen, en los discursos narrativos, ha adoptado, por convención, ir más allá de una función meramente descriptiva e implica significados indirectos. Hay una categoría que Gubern (1992) le atribuye exclusivamente a los discursos audiovisuales, la codificación secuencial, que explora las posibilidades de descripción y significación propias de la imagen móvil o imagen en movimiento.

De estas cinco categorías, profundizaremos las dos últimas, los conceptos que consideramos fundamentales para el estudio de las alteraciones del personaje animado: el estilo y las figuras retóricas de significación.

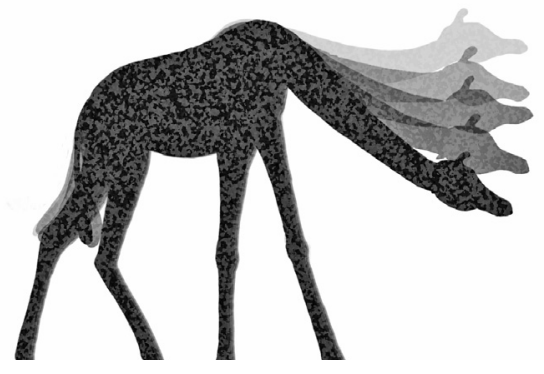




\section{El Estilo}

"La forma (como invención) no viene determinada sólo por
las propiedades físicas del material sino también por el estilo
de representación de una cultura o de un artista concreto"

(Arnheim, 2000:109).

El estilo en la representación gráfica incluye, en ocasiones, el uso de diversas transformaciones, de la misma manera como ha ocurrido en la historia de las obras pictóricas. La definición de un estilo en una obra, no necesariamente conserva una noción general definida, ya que depende del método de análisis empleado y de las particularidades específicas de su contexto de creación. Moralejo (2004) explica que el estilo puede ser entendido de dos maneras: el "estilo histórico", concebido de forma amplia y absolutista, que determina señales de identidad de una época, lugar e incluso una persona, o el de una "caracterización sígnica y expresiva" personal o grupal, condicionada por las pretensiones de algún tipo de manifiesto. Sin embargo, el autor plantea que el estilo "se forja en el trabajo del artista para resolver problemas concretos que se plantean en la temática iconográfica o en las exigencias funcionales" (Moralejo 2004:127). El Gótico, por ejemplo, nació de una cierta manera de construcción de catedrales, así como el Impresionismo, surgió de la necesidad de pintar la impresión o estimulo del instante y como reacción contra el arte tradicional de la época que impedía otras expresiones artísticas. "Si los estilos diferían, tenía que ser porque las intenciones cambiaban” (Gombrich, 1982). Moralejo también destaca que los estilos presentan "una ley sistémica que permite asociaciones de orden cuantitativo", lo cual tiende a reducir a fórmulas las

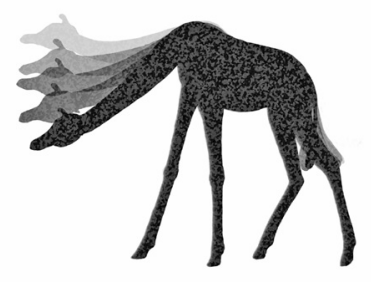
cualidades del estilo y a evidenciar un patrón, una constancia. Según el planteamiento de las técnicas visuales que desarrolló Donis A. Dondis (1976), el expresionismo está relacionado directamente con el criterio de representación en los dibujos animados, pues emplea la exageración para distorsionar la realidad con el propósito de intensificar los sentimientos. Las técnicas visuales que lo circunscriben, según Dondis, son la espontaneidad, la actividad, la complejidad, la audacia, la variación, la discursividad, la irregularidad, el experimentalismo, la verticalidad, la distorsión y la exageración, que permiten inferir un sistema de equivalencias con base en lo anteriormente mencionado por Moralejo.

La identificación de las alteraciones formales en los personajes de dibujos animados requiere que, en primera instancia, se realice una caracterización de las formas visuales dadas, para luego encontrar atributos similares, según su autoría en un determinado período. Como lo ha expresado Gombrich (1982): "ningún artista es independiente de predecesores y modelos, que él, no menos que el científico y el filósofo, es parte de una tradición específica y trabaja en una estructurada zona de problemas". Por supuesto, la animación no escapa de esta condición, por lo cual se ha evidenciado que los modelos de transformaciones dados en la imagen estática luego se hayan dispuesto en un esquema general en el dibujo animado, determinados por en el contexto de las producciones de los nacientes estudios de animación. 


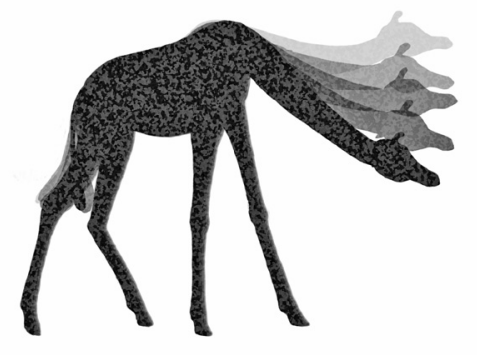

\section{La constancia fisonómica: la caricatura}

Entre otras concepciones, la caricatura ha sido definida como un método para realizar retratos donde prevalecen rasgos distintivos de la persona, mientras que otros elementos que la componen, son transformados. Según Ernst Gombrich, en el ensayo La máscara y la cara (1973), la forma de percibir y reconocer un rostro se basa en la separación y selección de lo que podría considerarse esencial; para ello utiliza el término "constancia fisonómica"; una cualidad que proporciona rasgos de identidad al individuo, a pesar de que se vea afectado por el tiempo o por las diferentes configuraciones generadas a través del movimiento. La "constancia fisonómica" ha sido analizada por autores como Leonardo Da Vinci, Rodolphe Töpffer y Charles Le Brun, cuyos métodos de segmentación y ubicación espacial de los elementos constitutivos o sub-entidades del rostro, se basan en experimentar con las posibles transformaciones para obtener diferentes expresiones faciales en el retrato, proceso muy similar a la división del rostro en Kinésica por parte de Paul Ekman.

La "constancia fisonómica” o "rasgos permanentes", como lo denomina Töpffer (Gombrich, 1982), están determinados bajo una estructura definida de composición. En el caso de la obra pictórica, donde el modelo o referente posee un complejo orden y ubicación espacial de partes que lo constituyen y que al ser representado adopta otras proporciones siendo aún reconocido, sin ser necesariamente un retrato "realista" del modelo: con lo cual Gombrich (1982: 299-300) concluye "no puede ser una transcripción de lo visto, pero tampoco puede ser una transcripción de lo recordado", debido a que se encuentra bajo un carácter expresivo, es decir, su pretensión no es representar la viva imagen del modelo.

Dos factores, por lo tanto, caracterizan la caricatura: la intención de conservar la identidad de lo dibujado, lo cual comprende un conocimiento adecuado de la expresión gestual, y el carácter irreal (grotesco o fantástico) de lo dibujado. De igual manera, con base en estos dos factores, se pueden caracterizar las alteraciones formales en el dibujo animado, en el cual se busca mantener la constancia fisonómica del personaje, oscilando entre las alteraciones producidas por la acción y el estado "normal" de su apariencia. Gombrich (1973:58) describe que uno de los rasgos principales de la caricatura es su "tendencia a la distorsión y a la exageración”, donde ocurren con frecuencia cambios de posición, inclinación, tensión y escala proporcional. Incluso, cuando se produce una sustitución o transformación de la apariencia humana por la de un animal o un objeto inerte (metamorfosis), es posible identificar la constancia fisonómica del personaje.
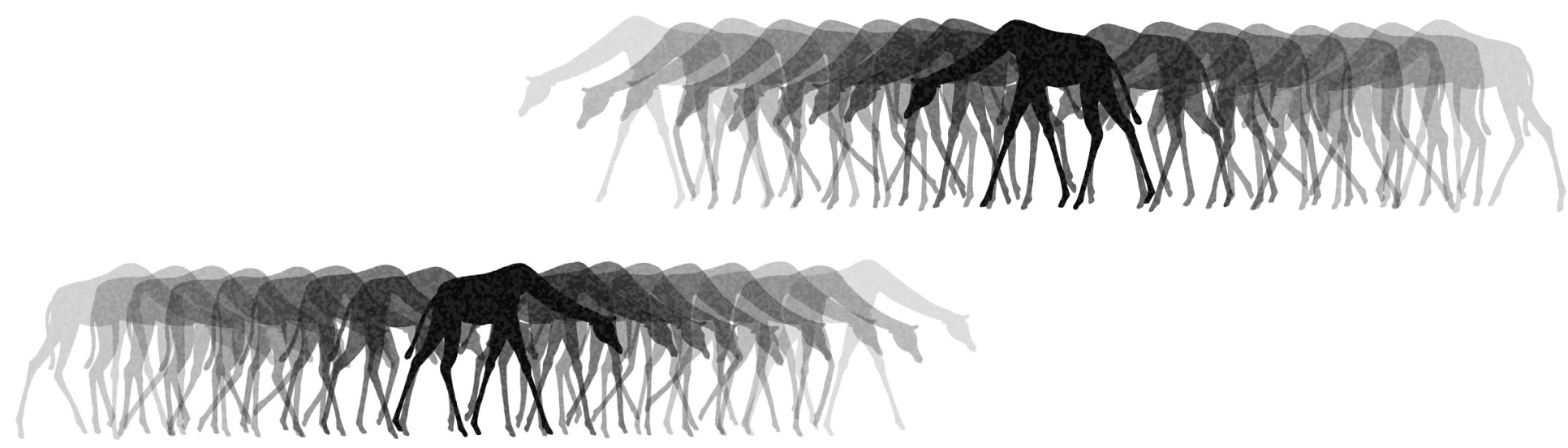
La caricatura no está exclusivamente dedicada a la hilaridad o la crítica. También se emplea en la expresión de diversos estados emocionales y en la representación de acciones como, por ejemplo, el desplazamiento (basado en elementos dinámicos), que ha sido explorado en movimientos artísticos como el futurismo, el dadaísmo, el surrealismo y el expresionismo, entre otros. Gombrich (1982:306), en ese sentido, menciona el "derribo de las barreras entre la caricatura y el arte" con la presentación de ejemplos como El Grito de Edvard Munch, caso particular pero determinante para la observación de las expresiones gestuales dadas a través de un proceso de transformación o también en La Metamorfosis de Narciso de Salvador Dalí, cuya posición permite identificar en la mano a Narciso y viceversa, generando contraste entre las dos formas pero conservando los rasgos permanentes.

En el dibujo animado, la constancia puede determinarse bajo el contraste de posiciones de menor o mayor grado (dependiendo del uso de alteraciones formales y del timing ${ }^{5}$ que percibe el ojo), debido a que establece varios estados en el personaje animado, pero sin posibilitar el mismo modo de contemplación que se da en la imagen estática.

\section{Las Figuras de significación o tropo}

Como se ha mencionado hasta el momento, la caricatura tiende al uso de la exageración o hipérbole, una de las más reconocidas figuras de la retórica. Gombrich (1998) describe que la caricatura además de recoger una serie de elementos para transmitir una idea o cadena de ideas (condensación), también se basa en la "metáfora natural" para expresar el contraste de símbolos o dualidades que puede inferir valores negativos o positivos. Por ejemplo, la oposición entre la luz y la oscuridad, ha simbolizado a lo largo de la historia de la imagen, la relación entre el bien y el mal. Así mismo describe el uso de la personificación, no sólo por medio de la transgresión del retrato, cuyo individuo puede ser vinculado con un animal, sino en la elaboración de conceptos abstractos como la paz.
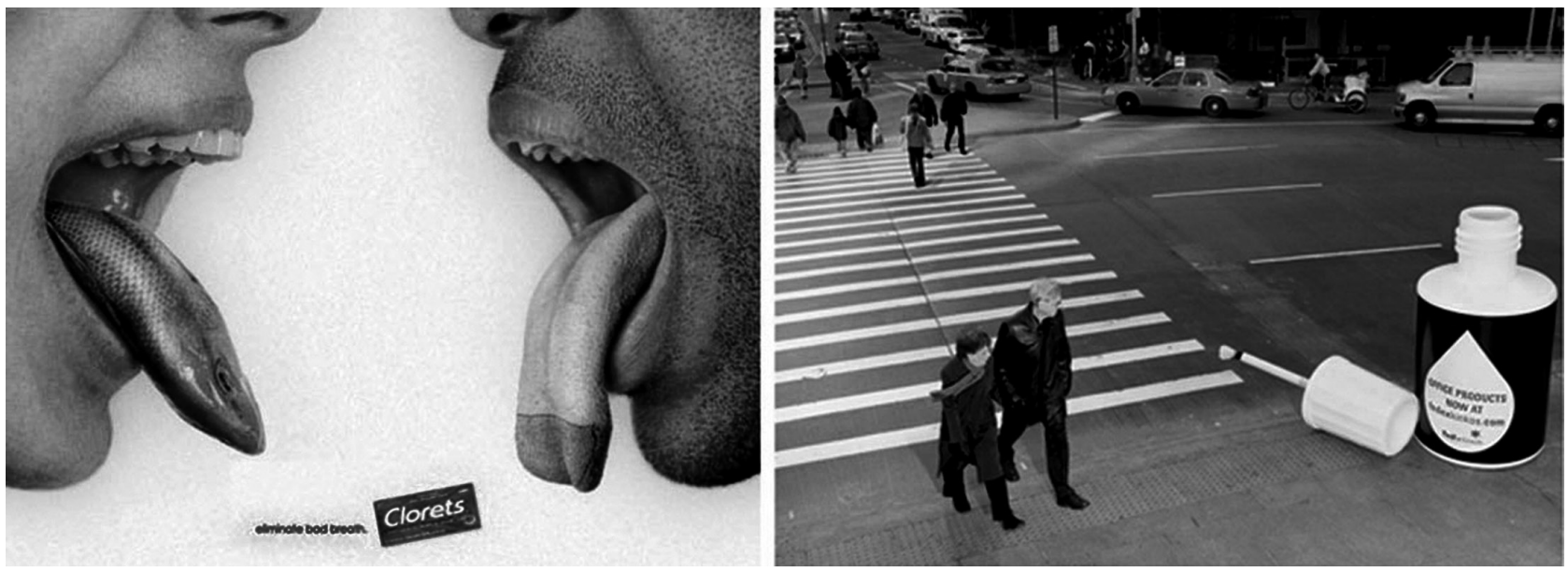

Figura $\mathrm{N}^{\circ}$ 2. El tropo en la imagen 
Las figuras retóricas visuales han sido empleadas de manera sistemática en la comunicación persuasiva. Según Ricoeur (1977:86) el tropo es "una figura de sustitución a nivel de la palabra", es decir que predomina el cambio de sentido o sustitución al designar objetos, cualidades o acciones diferentes a los que aparentemente evoca. Entre las más comunes están:

- La hipérbole, que consiste en la exageración de un hecho, característica o actitud que puede remitir a un exceso o un defecto. La caricatura es tal vez el caso más contundente. - La metáfora, que es una expresión que aparece según el contexto y que permite comparar la transferencia de una cosa a otra (Moliné, 2000). Se basa en la similitud de la forma o del contenido. Por ejemplo, la rosa roja por el amor.

- La sinécdoque, que expresa el menos por el más o la parte por el todo. Es una figura de inclusión. Por ejemplo, la mano de un escritor representa al escritor.

- La metonimia, es la figura de sustitución y contigüidad que cambia un elemento por otro sin que por ello la interpretación resulte distinta. Los elementos guardan una relación de contigüidad, por tener una relación de causalidad (como la pluma por el escritor, la sangre por la violencia o la risa por la alegría) o simplemente por estar yuxtapuestos en una escena visual (Toro, 2005). Un ejemplo es la obra de Giuseppe Arcimboldo "Water", en la cual, los elementos que componen la imagen representan su función o fundamento.

- La paradoja, resalta el absurdo de ideas preconcebidas. Zúñiga \& Danghelly (2009) plantean que, junto a la metáfora, son recursos imprescindibles del imaginario del hombre que exhibe mundos fantásticos e incontrolables para contradecir el mundo real (característico de los dibujos animados).

- La personificación, proveniente de la fábula, sirve para dotar de vida los objetos inertes, como por ejemplo el reloj o el candelabro en "La Bella y la Bestia", o para dotar de humanidad a los animales, como ha sucedido con el ratón Mickey o Bugs Bunny.

En el dibujo animado se emplean hábilmente los tropos para relacionar conceptos o para trabajar las reacciones de los personajes.

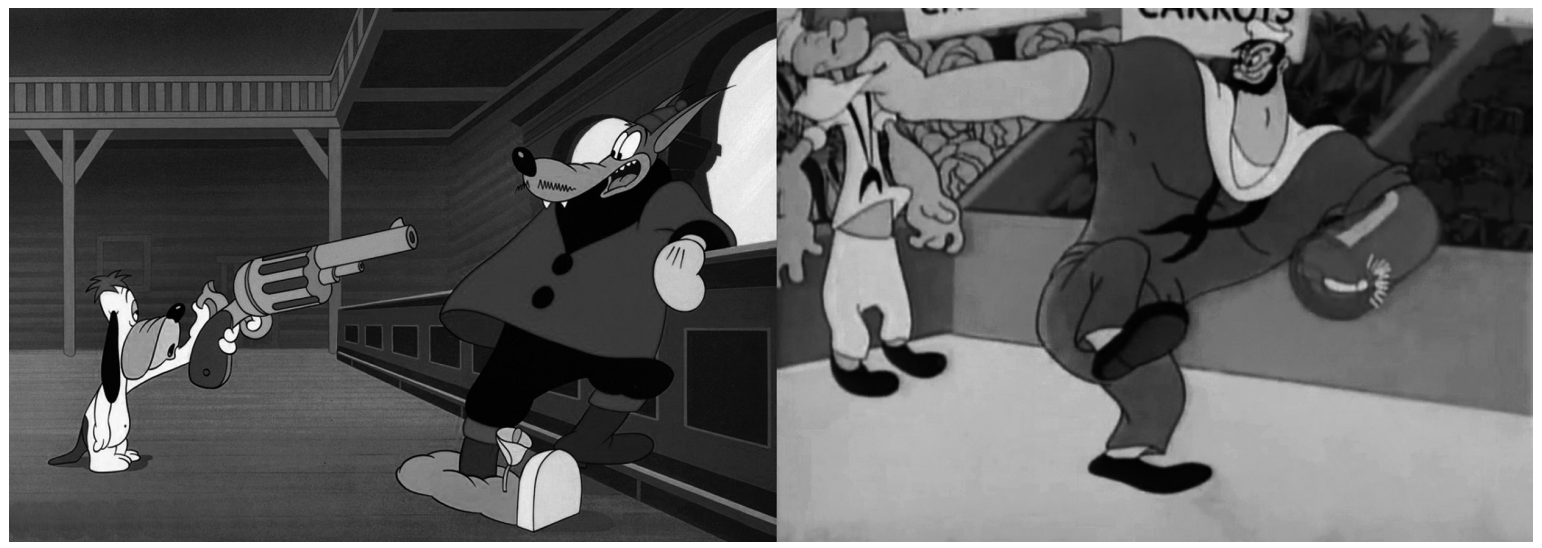

Figura $N^{\circ}$ 3. En la imagen de la izquierda (Droopy) describe "con un pie en la tumba"; en la imagen de la derecha (Popeye) el brazo de Brutus se transforma en una barra de dinamita encendida, como refiriéndose a un "golpe explosivo". 
Hemos presentado un rápido panorama de la noción de dibujo animado y los elementos estilísticos y semánticos fundamentales que lo posibilitan; tanto desde la perspectiva de la configuración de personajes, como desde la articulación que se hace de ellos en determinados contextos narrativos. Ahora, revisaremos un poco más a fondo los aspectos básicos de la imagen en movimiento: el fundamento conceptual que permite producir la ilusión de movimiento de los personajes animados.

Hemos presentado un rápido panorama de la noción de dibujo animado y los elementos estilísticos y semánticos fundamentales que lo posibilitan; tanto desde la perspectiva de la configuración de personajes, como desde la articulación que se hace de ellos en determinados contextos narrativos. Ahora, revisaremos un poco más a fondo los aspectos básicos de la imagen en movimiento: el fundamento conceptual que permite producir la ilusión de movimiento de los personajes animados.

\section{La imagen y el movimiento}

Ahora, estudiaremos los factores que determinan la percepción y la configuración de la imagen móvil y que contribuyen, por homología, al planteamiento de la noción de alteración formal en los dibujos animados. La animación procede, histórica y metodológicamente, de la imagen fija, pero difiere de ella en la manera de ser percibida, pues el medio de expresión es diferente. Esta homología, según Umberto Eco (1970), determina que así los elementos pertenezcan a distinto orden, se pueden interpretar y señalar mediante esquemas estructurales, que pueden resultar similares.

La aplicación de la homología estructural facilita un terreno en el que moverse para adelantar hipótesis acerca de la conexión de dos fenómenos, sin que, por otra parte, la conexión se haya establecido a priori como condición de la inteligibilidad del fenómeno, y teniendo plena consciencia del hecho de que la homología se presenta únicamente porque para describir e interpretar los diversos fenómenos se recurre al convencionalismo de ciertos módulos descriptivos que permiten su determinación (Eco, 1970:196).

\section{Imagen móvil y fija en el dibujo animado}

La imagen móvil o cinética puede ser entendida como la síntesis de imágenes estáticas consecutivas que al ser proyectadas generan la sensación del paso del tiempo, siendo cada imagen inestable y efímera en la creación de movimiento. En el cine, la imagen móvil se produce gracias a la captura fragmentada del movimiento real que luego se recompone en la proyección. Este es, por supuesto, un proceso de animación como formato (Sánchez Noriega, 2002), pero la diferencia con la animación, propiamente dicha, radica en que en ésta el movimiento es elaborado en la etapa de producción, mientras en el cine es registrada; en la animación las imágenes se planean y se yuxtaponen en un proceso minucioso de diseño y producción del movimiento. Ahora, lo tienen en común que una sola imagen no describiría en su complejidad las historias que intentan relatar. Ambos recursos necesitan de la simulación de movimiento como fenómeno de fusión de las imágenes que se captan a través del ojo. 
Deleuze (1984) establece que el movimiento en el dibujo animado y en el cine comparte la misma base, debido a que el dibujo en sí mismo no constituye una postura finalizada, sino la descripción de la figura haciéndose y deshaciéndose.

Lo que representa el dibujo animado no es la figura en un instante, sino el movimiento que la figura describe; es decir, una imagen móvil compuesta por trayectorias y puntos en el formato que permiten percibir la continuidad del movimiento.

La presencia de alteraciones formales en el dibujo animado puede deberse al uso de transformaciones que han sido utilizadas en la obra pictórica (por la influencia de alguna época o lugar) y están compuestas por elementos ilusorios que el espectador interpreta como dinámicos. Los elementos dinámicos que ocasionan desequilibrio o tensiones en la representación de imágenes fijas, evocan el movimiento, lo "metaforizan", como lo expresa Arnheim (2000), ya que el observador lo percibe, aunque nada se mueva materialmente. El dibujo animado requiere ser discernido en un determinado período de tiempo y por ello utiliza recursos de representación que afectan su configuración en la pantalla, entre los cuales, se puede dar el uso de transformaciones formales para incrementar la ilusión de movilidad, propios de la imagen estática, como los elementos dinámicos.

\section{Elementos dinámicos en la imagen estática}

No tienen una materialidad propia en la composición. Lo dinámico está asociado con el concepto de temporalidad en relación con el espacio. La tensión, el equilibrio, la orientación, la profundidad y el ritmo hacen parte de los elementos dinámicos según Villafañe (2006), principalmente aplicados en la imagen estática para producir la sensación de movilidad. György Kepes (1976) explica que estos elementos son medidos por el ojo y que de acuerdo con cada variación produce una experiencia diferente; permiten delimitar y observar similitudes empleadas en la obra animada de forma no permanente.
La tensión en la imagen estática cumple la misma función que el movimiento en la imagen móvil. Villafañe denomina "elementos activadores" a aquellos de los que depende la imagen fija para obtener dinamismo: la orientación, la profundidad, el contraste cromático y la proporción.

La orientación actúa a nivel espacial, como la perspectiva, la dirección, la inclinación y la asimetría. Se diferencian precisamente de los ejes que emulan reposo, estatismo o equilibrio. Precisamente, el equilibrio, en el dibujo animado, es un elemento clave para entender el movimiento, pues puede considerarse como un punto de reposo en la representación donde aparentemente no hay movimiento. El equilibrio según Donnis A. Dondis (1976:37) es un proceso de "estabilización que impone a las cosas vistas un eje"; un eje vertical y uno horizontal que miden el equilibrio o desequilibrio de acuerdo a una posición de la figura que sugiere movimiento. Al eje vertical, le llama "eje sentido", que es el que, dada nuestra naturaleza gravitacional, indica la dirección de lo estable.

Otro elemento es la profundidad, que otorga sensación de progresión. La tensión es producida a través de las líneas que convergen en los puntos de fuga y aplica también en el contraste cromático que comúnmente se observa en la perspectiva aérea o atmosférica.

La proporción, según Villafañe (2006:161), es la relación cuantitativa entre un objeto y los elementos que la componen y también la relación entre las partes de dicho objeto. Panofsky (2000:78) resalta que la teoría de las proporciones "establece relaciones matemáticas entre los distintos miembros de un ser viviente, en particular de los seres humanos, en la medida en que estos seres se consideran como objetos de una representación artística”. Observa, además, que se pueden diferenciar las teorías de proporción que vinculan movimiento y organicidad en comparación con otras que son rígidas e impiden una "libertad artística" y que pueden conllevar a distinguir elementos de estilo en la obra. Panofsky (2000) ha categorizado dos tipos: la proporción objetiva y la proporción técnica, en las que respectivamente se producen contrastes de “imitación” o de "reconstrucción". 
La proporción objetiva se refiere a la relación entre las partes de la figura, donde no hay una medida definida, ya que la búsqueda se fundamenta en "captar la belleza” basándose en la observación. Por eso, los griegos realizaban variaciones en las dimensiones de las estatuas para que en determinado punto de vista se diera armonía. También, cuando tenían en cuenta las dimensiones variables que deriva del movimiento observado en la contracción y expansión del cuerpo, principalmente en los músculos. En cambio, la proporción técnica está sujeta a precisiones de igual medida y repetida en el formato, es decir, estaba regida bajo un módulo absoluto que en ocasiones detallaba una figura rígida, como por ejemplo los grabados egipcios.

El ritmo es, por otra parte, un elemento dinámico de gran importancia y común en las clasificaciones que han realizado un gran número de teóricos gestalistas ${ }^{6}$. De carácter espacial, está ligado a la tensión para generar la impresión de movimiento y se caracteriza por tener periodicidad: (repetición de elementos o grupos idénticos de dichos elementos) y estructuración (variada e incluye pausas o silencios).

Como elemento dinámico, el ritmo ha sido empleado por diversas corrientes artísticas para simular el movimiento... el Pop Art, el Op Art, el futurismo y el dadaísmo están basados en la cronofotografía, recurso mediante el cual los elementos parecen repetirse en diferentes posiciones. Aparece también en las obras escultóricas de Peter Jansen.

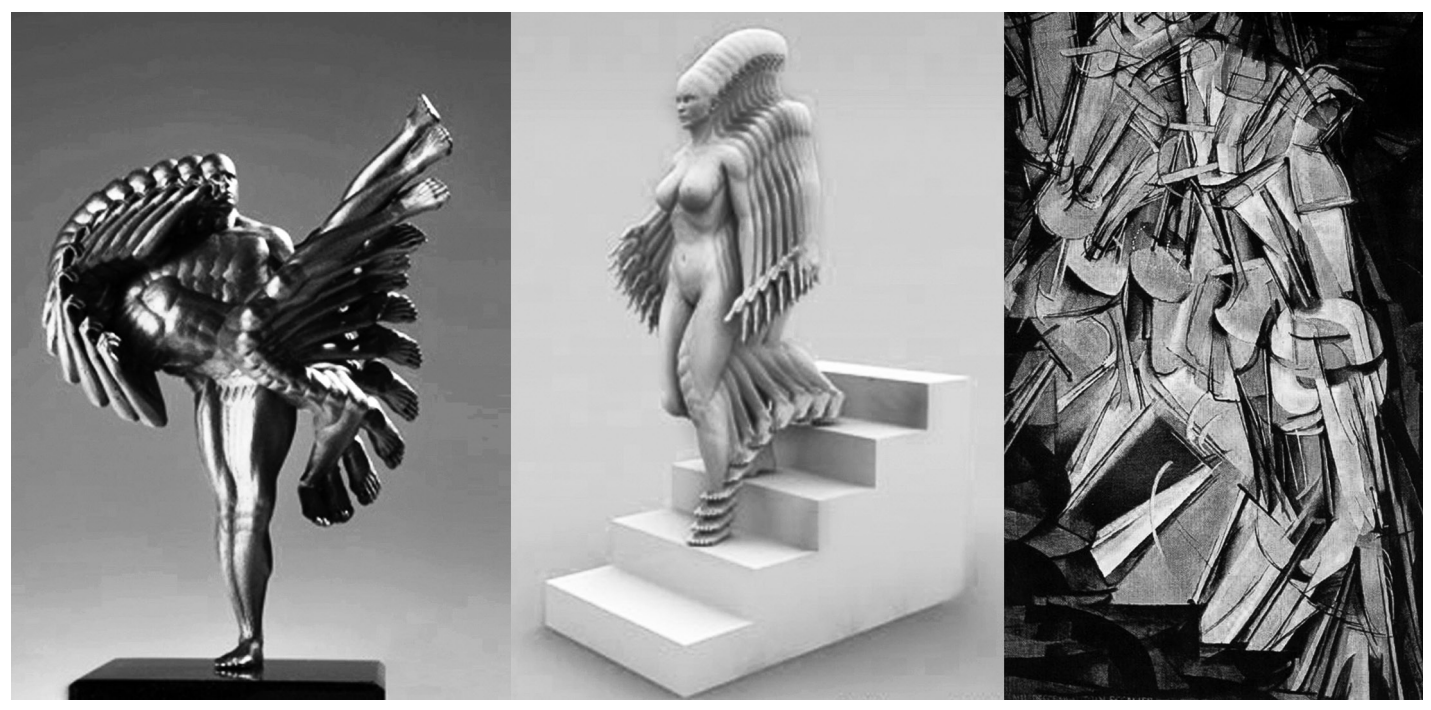

Figura $\mathbf{N}^{\mathbf{0}}$. Esculturas de Peter Jansen y "Desnudo bajando una escalera, detalle, 1912”, Marcel Duchamp.

En la figura animada, el ritmo se desliga de la tensión formal (excepto en el uso de las alteraciones formales), pues ya no es exclusivo de la espacialidad, sino que influye en la temporalidad del relato. Sin embargo, presenta características similares como la periodicidad y la estructuración, como elementos alternos, y con base en ellos, produce acciones primarias, secundarias y terciarias. El ritmo en el desarrollo del movimiento animado se presenta dentro de los doce principios de animación, bajo el nombre de timing. 
En relación con la tensión, la línea puede asumir un desempeño dinámico, además de su función primordial de contornear la figura, pues permite visualizar un recorrido, trazando una continuidad de elementos o siguiendo un patrón (ley de continuidad), ya que indica dirección. Incluso, en las manifestaciones de cierre de las figuras ${ }^{7}$, referida a las zonas faltantes u ocultas donde se da una tendencia a seguir una línea de lectura sugerida en el espacio que el cerebro tiende a completar. Como el caso de la ilusión de Poggendorf, que consiste en una ocultación parcial que intensifica el efecto de movimiento -explicado por Gombrich (1993) por medio de la "Cantoria de Donatello”- También existen otras ilusiones producidas a través de la tensión, la distancia, la dirección, la proximidad y la posición de los elementos, considerados por Gubern (1992) como errores perceptivos, pues se constituyen en anomalías que alteran la característica de la forma percibida.

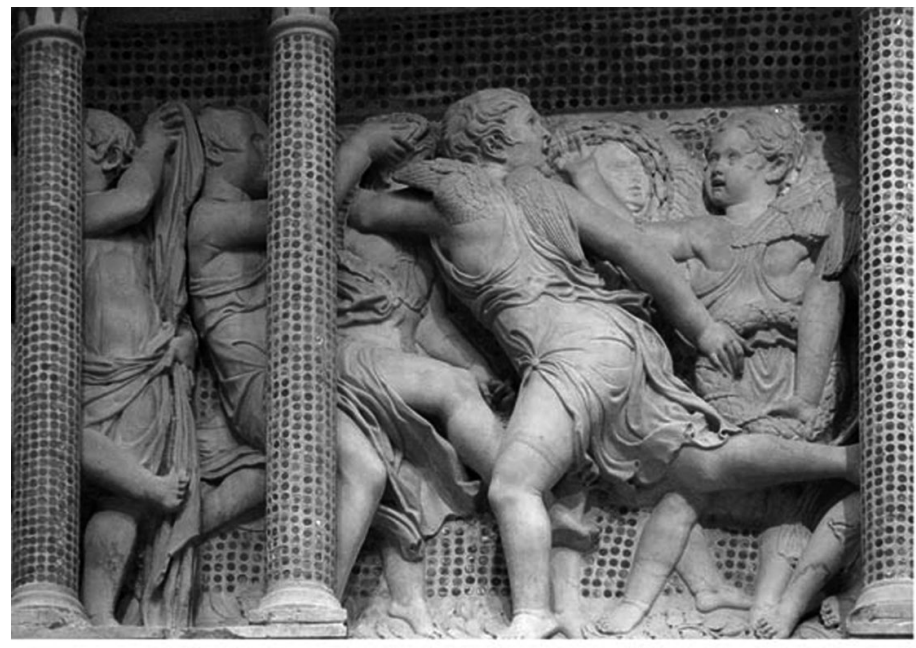

La Cantoria de Donatello

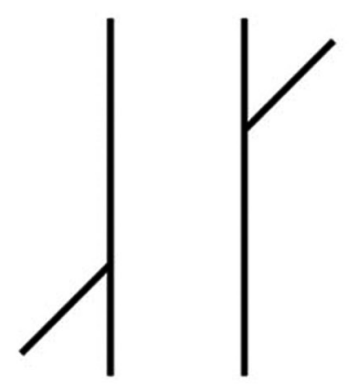

Esquema ilusión de Poggendorf

Figura $\mathbf{N}^{\circ}$. Cantoria de Donatello e ilusión de Poggendorf

Otra forma de concebir el movimiento se debe al recuerdo de las experiencias sensoriales almacenadas por el individuo. Rudolf Arnheim (2000) presenta el ejemplo de la observación de la escultura de un bailarín. El observador ve el objeto y siente el movimiento con base en los recuerdos acumulados de ese tipo de acciones del mundo físico (presentaciones coreográficas) y se engaña inconscientemente, interpretando una insinuación de movimiento que no existe. Esto es posible gracias a los "factores naturales" que operan en la construcción de la percepción del movimiento, señalados por Kepes (1976), e implica asociaciones visuales y no visuales.

La imagen estática utiliza elementos dinámicos para emular el movimiento, pero, como acabamos de ver, es una construcción que realiza el sujeto mediante el conocimiento, para interpretar y re-interpretar cargas culturales, sociales y afectivas, transformando la representación y otorgándole atributos de significado y temporalidad 


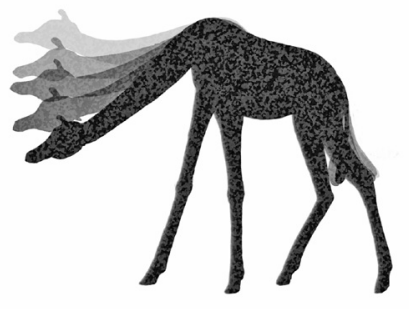

\title{
Complementar el pasado y prever el futuro
}

\author{
"No podemos estimar el paso del tiempo en un cuadro sin interpretar el \\ acontecimiento representado" (Gombrich, 1993).
}

En la apreciación de la imagen estática la percepción del movimiento requiere bastante tiempo de observación por parte del canal visual y el córtex cerebral. En este proceso tan complejo, el espectador discrimina contenidos de acuerdo con su interés y dependiendo de los niveles de jerarquía que posean los elementos de la composición. James Harris (Gombrich, 1993:41) ha mencionado que una obra pictórica representa un punto de tiempo o instante y por ello se convierte en un objeto de contemplación en el cual se escoge la "situación" adecuada. Si, además, la representación revela un conocimiento familiar para el espectador, él puede situar la obra estableciendo un pasado y futuro, que proviene de la comprensión de una acción; como por ejemplo, las obras basadas en mitología o religión en donde se puede reconocer la historia o un punto del relato.

Heinrich Wölfflim ${ }^{8}$ (Arnheim, 2000:464) expone el caso de otro tipo de simultaneidad con el tiempo, a propósito de la escultura de inspiración bíblica de Donatello en la que David sostiene una piedra en la mano y Goliat aparece ya vencido. Arnheim menciona que esta obra está fuera de la lógica de temporalidad del relato y, por lo tanto, el artista sintetizó en ella una acción representada en fases intemporales de un mismo evento, sin que por ello la obra pueda ser considerada absurda. Esta articulación también se produce en la imagen móvil: la relación de continuidad se debe al conocimiento y retentiva que percibimos como movimiento donde se establecen relaciones entre el pasado y el futuro, favorecidas a través de la narrativa.

Shaftesbury y Lessing (Gombrich, 1993:49) señalan que "la ilustración satisfactoria de una narración siempre sugerirá y facilitará la revocación y la anticipación, el barrido hacia atrás y adelante en el tiempo que proviene de la comprensión de una acción”. A esto agrega Gombrich (1993:51) que la acción se separa en fases y son esas unidades la que se experimentan en el tiempo, por medio del conocimiento.

Para sintetizar lo expuesto en este segmento, podemos concluir que el movimiento, como ilusión, se produce en el espectador como una relación entre los factores cognitivos de su sistema senso-perceptivo (es decir la percepción de una sucesión de imágenes y la proyección de cambios registrados por la cámara o realizados por el animador) y los factores socio-culturales de su experiencia (la identificación de contextos de representación en un mundo relatado, en los que se presenta o no familiaridad con las acciones y los lugares en los cuales lógica e históricamente podrían haber ocurrido). El entrenamiento que hemos recibido culturalmente nos vuelve absolutamente sensibles ante la ilusión del movimiento, tanto en ciertas imágenes estáticas que lo sugieren, como en la imagen móvil propiamente dicha... Es inevitable para nosotros la percepción de profundidad y movimiento que produce una obra de Op Art o una película presentada en un sistema 3D.

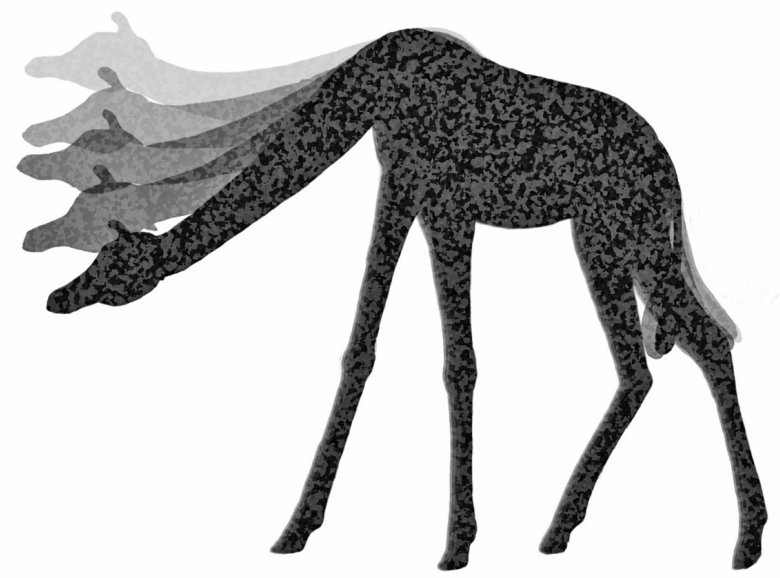


A continuación, pasaremos al segmento final en el que veremos cómo se emplea la distorsión del dibujo animado como recurso eficaz en la producción ilusoria del movimiento. Un recurso técnico y discursivo que incrementa los efectos dramáticos del relato en varios niveles de pertinencia.

\section{La alteración en la figura animada}

A continuación referiremos como alteraciones formales solamente las transformaciones producidas en el personaje animado, debido a que en él se pueden determinar cambios graduales que permiten contrastar estados de posición y establecer puntos espaciales que describan un antes y después perceptible por medio de los fotogramas. La alteración formal delimita toda una serie de cambios, modificaciones o sobresaltos generalmente observados en el take de animación, pero existen otros usos que pueden llevarse a cabo. Es preciso, por lo tanto, definir características generales de transformación - de tipo geométrico-, y a partir de allí realizar un categorización cuyos criterios se constituyan con base en los conceptos mencionados al comienzo, como la distorsión, la deformación y la transformación, pero ordenados de tal manera que posibilite la comparación de posiciones, según la ubicación espacial de la figura animada y situada en los ejes insinuados que le correspondan.

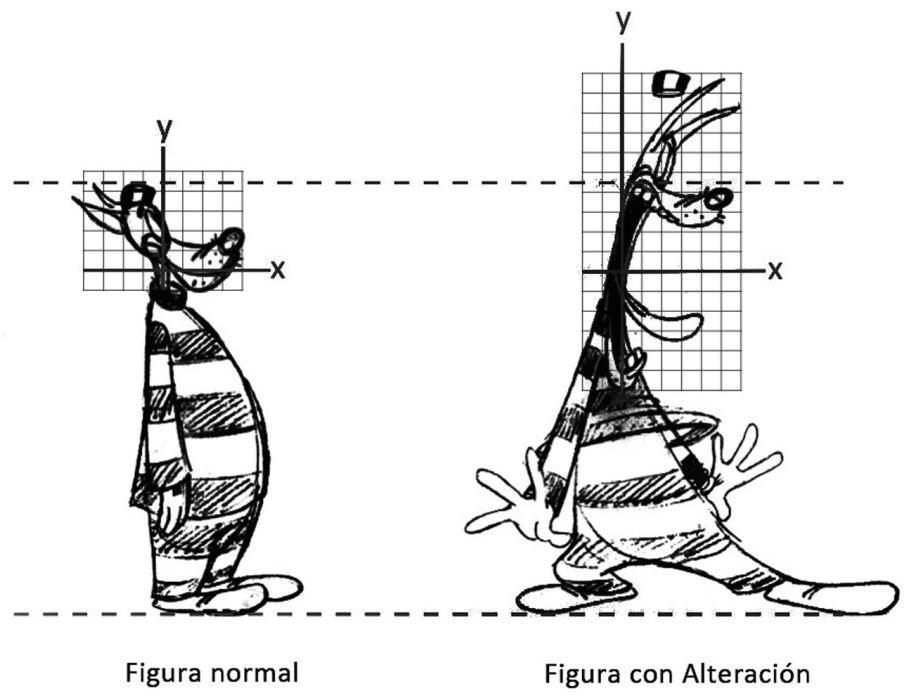

Figura $\mathbf{N}^{\circ}$ 6. Imagen extraída de Model sheet $\mathrm{N}^{\circ} 145$ (hoja de personaje) de producción Northwest Hounded Police.

\section{Transformación y Representación}

El dibujo animado se caracteriza por representar el movimiento a través de la secuencialidad de las imágenes, expresando acciones e ideas dentro de un relato. Cuando una representación gráfica y su referente se relacionan por semejanza formal, se le denomina icónica, y puede ser producida de diversas maneras por medio del dibujo, la escultura, la pintura o la fotografía. Las representaciones icónicas están determinadas por escalas o valores de iconicidad, es decir los niveles de similitud entre lo representado y el referente. Gubern (1992) clasifica la imagen icónica en estática, secuencial y móvil. La estática corresponde al dibujo, la pintura, la escultura y la fotografía; la secuencial, a aquellas manifestaciones en las cuales se disponen las imágenes en algún criterio de secuencialidad, como en el cómic y la fotonovela, y la imagen móvil corresponde a los medios audiovisuales como el cine, la televisión y la animación. 


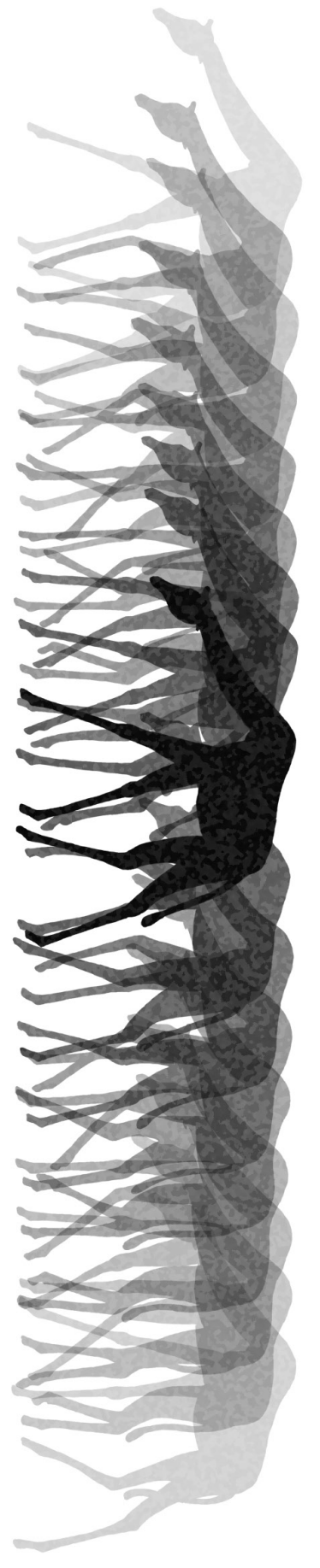

El grupo $\mu$ (1993) describe que la representación icónica en el campo visual, está determinada por una serie de operaciones, llamadas transformaciones, que influyen en el reconocimiento del modelo en relación con la obra representada, principalmente, a propósito la imagen material ${ }^{9}$ (estableciendo, además, una distancia entre referente y significante). Estas transformaciones son clasificadas y definidas bajo el nombre de transformaciones geométricas, analíticas, ópticas y cinéticas. Las transformaciones geométricas abarcan cambios de posición, traslación, rotación, simetría, homotecia (que corresponde a una reducción o ampliación de la figura, es decir, el cambio en su escala), proyecciones (deformantes, que sólo conservan algunas propiedades de la figura, acentuando la polisemia del ícono) y topológicas (que delimitan niveles de proximidad). Las transformaciones analíticas, están relacionadas con los estímulos presupuestos, como la luminosidad, la saturación, la dominancia cromática y su relación instrumental, es decir, se refiere a la forma en que se presentan los aspectos físicos de la imagen, gracias a las condiciones de los estímulos y los mecanismos de afectación de la sustancia del soporte, como por ejemplo trazos fluidos, fuertes o débiles. Las transformaciones ópticas afectan las características físicas de la imagen por las condiciones de la percepción visual humana. Por ejemplo, la nitidez y la profundidad producidas por la visión binocular estereostópica o algunos defectos de la visión que permiten hacer transformaciones de acuerdo con el ángulo de visión o la fisiología. Finalmente, las transformaciones cinéticas implican el desplazamiento y distancia del observador y la imagen: la distancia que toma frente a ella evidencia que la textura al ser vista de cerca "no tiene significación icónica", a menos que se conciba la ambigüedad representacional de tipo fluctuante, como ocurre en algunas obras de Giuseppe Arcimboldo en las cuales las diferencias de proximidad permiten observar dos tipos de imágenes icónicas.

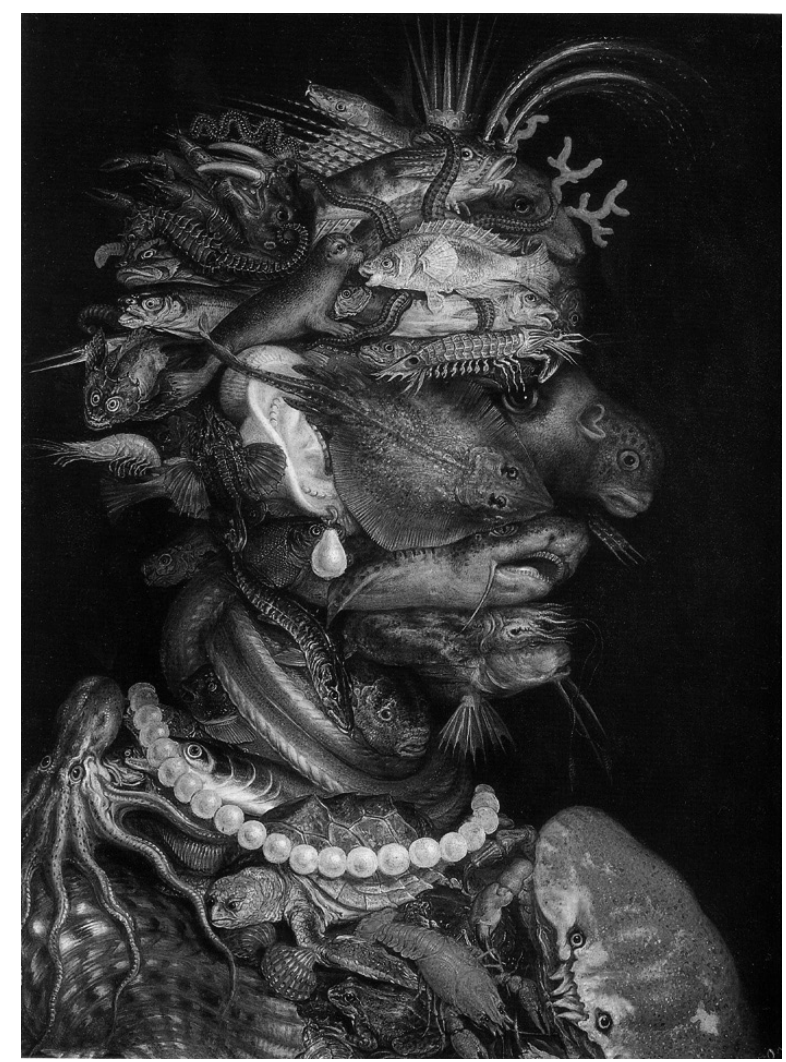

Figura $\mathbf{N}^{\mathbf{0}}$ 7. The Water, Giuseppe Arcimboldo 


\section{Deformación y distorsión}

Deformación y distorsión son términos que se utilizan para describir una representación visual que está sujeta a elementos dinámicos o cambios abruptos de la forma. En la mayoría de los casos, dichos cambios son exagerados en relación con el modelo referencial de representación. La denominación de distorsión y deformación en la imagen estática presenta una reglamentación de uso de acuerdo con una gran cantidad de alternativas, que es necesario organizar para entender o, por lo menos, para realizar una aproximación concreta sobre el uso de estas expresiones.

La distorsión se refiere, principalmente, a la imagen transgredida por fuera de los cánones existentes de proporción (según el estilo de la época) donde el irrealismo y el desorden son predominantes. Según Dondis (1976) "la distorsión pretende desviarse de los contornos regulares y a veces de la forma auténtica". László Moholy-Nagy (1947), por otra parte, explica la distorsión, dentro de una clasificación estructurada, como las transformaciones que poseen un significado plástico y uno literario, inmanentes en la imagen. El significado plástico alude al énfasis de la forma determinada por el cambio en sus propiedades, tales como la dimensión, la proporción o la concavidad, entre otros. Pueden haber cambios geométricos y orgánicos en múltiples formas, que en algunas ocasiones lleguen a presentar elementos sustraídos o agregados a la figura. Y el significado literario describe la caracterización expresiva de objetos o personas en la representación, empleando la analogía de los elementos que puedan estar vinculados con la imagen, regido bajo las figuras literarias propias de la caricatura o la publicidad. Moholy-Nagy específica que las alteraciones formales en la imagen también tienen una aplicación según la intención que deseen propiciar sobre el espectador, teniendo en cuenta la distancia y ángulo de observación, logrando que la alteración formal sea evidente. Al respecto, Gubern puntualiza (1992:121): "la obra es la distorsionada y el ser humano corrige esa distorsión". Una de las distorsiones que implican una función correctiva, es la anamorfosis, según la cual la figura sólo puede ser vista adecuadamente desde un cierto punto de vista que permite apreciar las proporciones correctas; la imagen toma una proporción clara y verosímil sólo desde un lugar determinado. Desde el arte clásico griego se venía empleando esta técnica, en la escultura... Estatuas cuyas cabezas son proporcionalmente mayores en relación con el cuerpo, que al ser vistas desde abajo, favorecen una apreciación coherente.
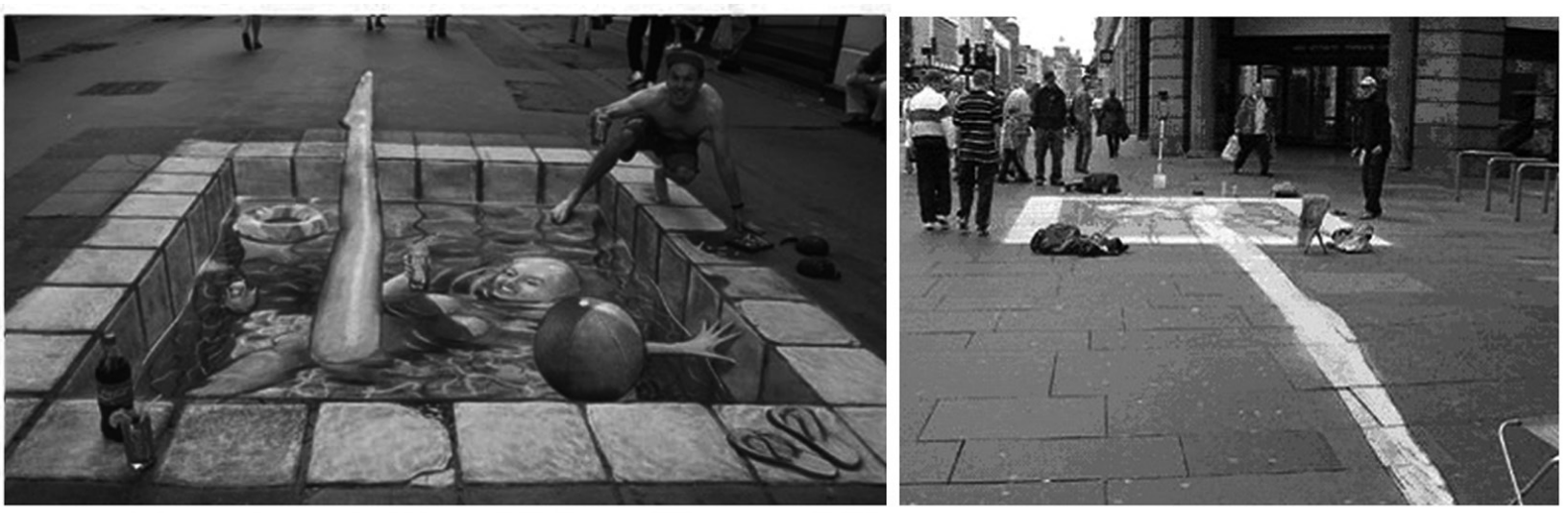

Anamorfosis desde dos puntos de vista, realizada por Julian Beever

Figura $\mathrm{N}^{\circ}$ 8. Anamorfosis 
Otra función que Moholy-Nagy aplica a la distorsión es el uso de la perspectiva, en donde establece lo que él llama "vision in motion"; la captura de diferentes ángulos o puntos de observación, propios del cubismo. En este tipo de imágenes, el retrato u objeto está representado bajo diferentes puntos de fuga y tiene detalles o acercamientos predominantes que conforman la totalidad de una acción. El uso de la perspectiva, como recurso "alterador" de un modelo percibido, implica tener en cuenta la visión del espectador y sus diferentes concepciones verosímiles de cómo percibe la forma. Román Gubern (1992) explica cómo el uso de la perspectiva central, desarrollada por Brunelecci, logró una gran influencia en la pintura del Renacimiento como simulación de lo verosímil, pues es un falso modelo de la visión humana debido a que "es una abstracción de lo que supone la inmovilidad de la mirada, condición fisiológicamente imposible”. Pareciera que el uso de la perspectiva, independientemente del número de puntos de fuga, es una pretensión que no llega a ser un modelo relacional propio de la realidad.

Remitiéndose a la óptica, la distorsión hace parte de las aberraciones de Seidel, que son recibidas por el ojo humano de la misma manera como ocurre en lentes y espejos; mientras que en el lente hay pérdida de nitidez o enfoque en la figura, por medio de la distorsión se producen cambios en la forma. Las aberraciones son clasificadas según Daniel Malacara (2004) en esférica, coma, astigmatismo, curvatura de campo y distorsión. Las primeras suceden como aberración esférica; coma y astigmatismo se rigen bajo la figura difuminada en bordes, direcciones o planos de posición, y los dos últimos comparten la tensión sobre la figura: la aberración de curvatura de campo, cuando al enfocar una superficie plana, no se distingue como tal sino que forma un arco hacia el interior, y la aberración por distorsión, cuando las líneas rectas se curvan, de tal modo que la forma del objeto o imagen se expande o contrae a partir de un eje central, produciendo distorsiones tipo barril o corsé (La distorsión de barril sucede cuando los lados se curvan hacia el exterior; en la fotografía se observa en objetivos o lentes de ojo de pez para fotografiar campos amplios, y la distorsión corsé, cojín o negativa, cuando los lados se curvan hacia dentro).

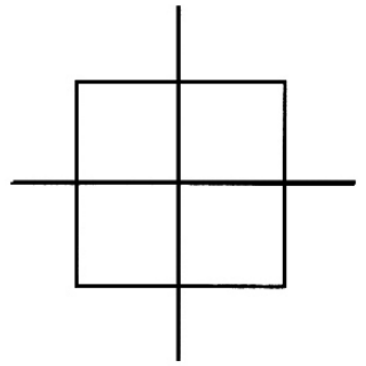

Objeto/ imagen

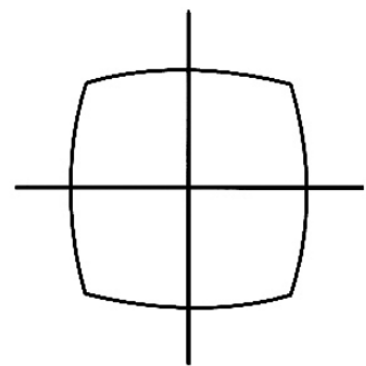

Imagen con distorsión en barril

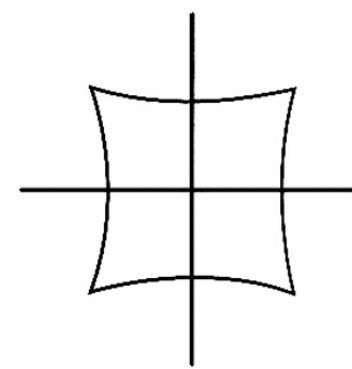

Imagen con distorsión en corsé

Figura Nº 9. de Malacara Daniel. Óptica básica.2 ed. México; FCE, 2004.P. 112 
Arnheim (2000) señala que la deformación "implica siempre una comparación de lo que es con lo que debería ser” (complementación y previsión), es decir, el objeto deformado como desviación de otro objeto. Pone el ejemplo del rombo, que se puede apreciar como una deformación de una figura cuadrada sujeta a tensión; sin embargo, dicha tensión se genera mediante la deformación y la distorsión de las proporciones que estructuran la imagen, haciendo que aparezca como la desviación de una base normativa (imagen hiperformalizada).

\section{Características de las alteraciones}

Las alteraciones presentan tres características generales:

1. Pueden emplearse conjunta o simultáneamente; es decir que la figura puede presentar alteraciones combinadas en el tiempo, como en "Your Face" (1978) de Bill Plympton. De igual manera, la alteración puede afectar una parte o la totalidad de la figura animada, sementando unidades formales que la componen con autonomía en su aplicación (ojos, boca, oreja, brazo, mano, dedos, etc.). Así pues, la figura animada es dividida en entidades y subentidades para su reconocimiento en el estudio. Un ejemplo de este caso se presenta en uno de los principios de animación como encoger y estirar, según las cuales se podría intervenir un brazo, la cabeza o todo el cuerpo del personaje.
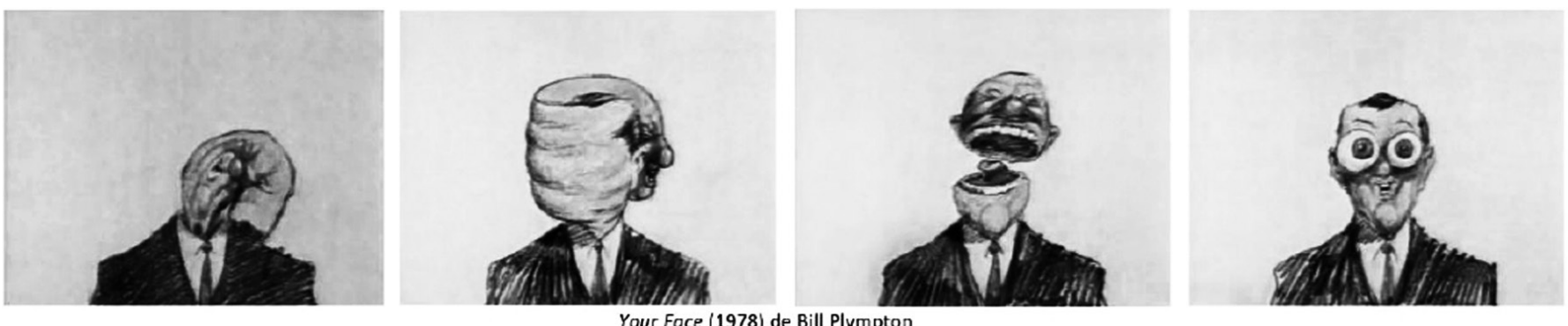

Figura N¹0. "Your Face" (1978) de Bill Plympton

2. La adaptación del comportamiento físico sobre las propiedades elásticas de los objetos estudiado en la Física, estableciendo que las alteraciones pueden ser permanentes o efímeras, donde el personaje animado se vea afectado a quedarse deformado ante una reacción o una interacción con otro elemento o regresar a su forma habitual.

3. Los movimientos micromomentáneos o imperceptibles, propios de la comunicación no verbal y que serán determinados como microalteraciones, constituyen casos de muy bajo nivel de percatación del ojo humano, dada su corta extensión espacial y temporal en el formato. Es conveniente señalar que el alcance de las alteraciones formales sobre un plano son tan variadas, que sólo puede indicarse la dirección y posición que toman, y que pueden estar apoyando el uso de una figura de significación o tropo. 


\section{Clasificación de las alteraciones}

Se establecen seis aspectos generales de alteración formal para dibujos animados: alteración por distorsión, por multiplicación y adición, por tamaño, por posición, por división o sustracción y por metamorfosis.

Alteración por distorsión: Se refiere a la figura alterada en relación con un punto central en su eje, donde se da un estiramiento o encogimiento mediante la tensión, sin importar el ángulo de dirección y la división de la figura. Puede ocurrir un cambio de proporción asimétrico de acuerdo con la dirección escogida (tomado de la distorsión señalada en aberraciones ópticas). Un ejemplo predominante se encuentra en estirar y encoger. Además de este tipo de distorsión existen otras donde se aplican formas geométricas a la figura o donde la tensión se ejecuta en partes o selección de puntos en la figura, entre ellas están:

Distorsión sesgada: Implica que la figura posee una tensión en un punto horizontal o vertical conservando un punto fijo estático en el centro y en uno de sus extremos o esquina.

Distorsión esférica: Es la aplicación en la figura donde una especie de lente parecido a una lupa sobre una superficie, toma una expresión esférica, donde aparenta un volumen y deformación.

Distorsión curva: El objeto no puede tomar una forma lineal, su figura está sujeta a mantenerse curvada.

Distorsión turbulenta: Son los casos del espiral y molinete (una espiral con líneas no continuas, con diferentes líneas de inicio y fin, dirigidas a un vértice), que generan desplazamientos desde una ubicación de partida fija.
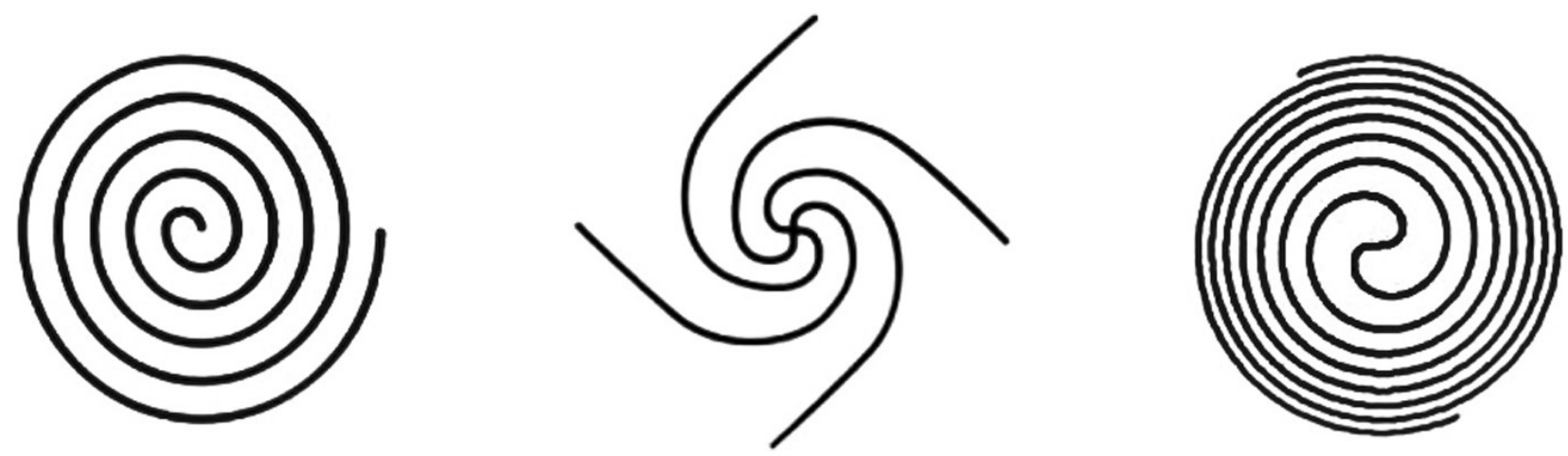

Figura $\mathbf{N}^{\circ} 11$. 
Distorsión por ondas: Es la reproducción continua igual o asimétrica de ondas donde la forma puede basarse en líneas curvas, cuadrados, triángulos (Zig-zag), círculos, tramas de puntos, pueden tener diferentes amplitudes y dirección. La figura puede tomar características de desplazamiento de fluidos.

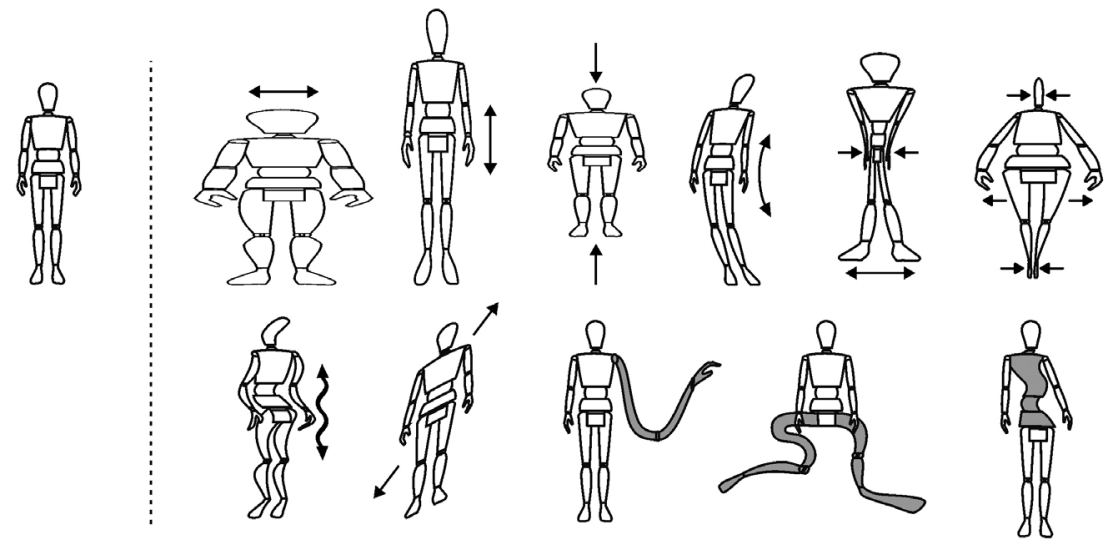

Figura $N^{\circ} 12$. Ejemplos de Alteración por Distorsión corporal

Alteración por multiplicación o adición: Pueden visualizarse dividiendo el cuerpo en subentidades, ya que por una parte la mínima expresión de esta alteración puede estar en un ojo o incluso en la pupila.
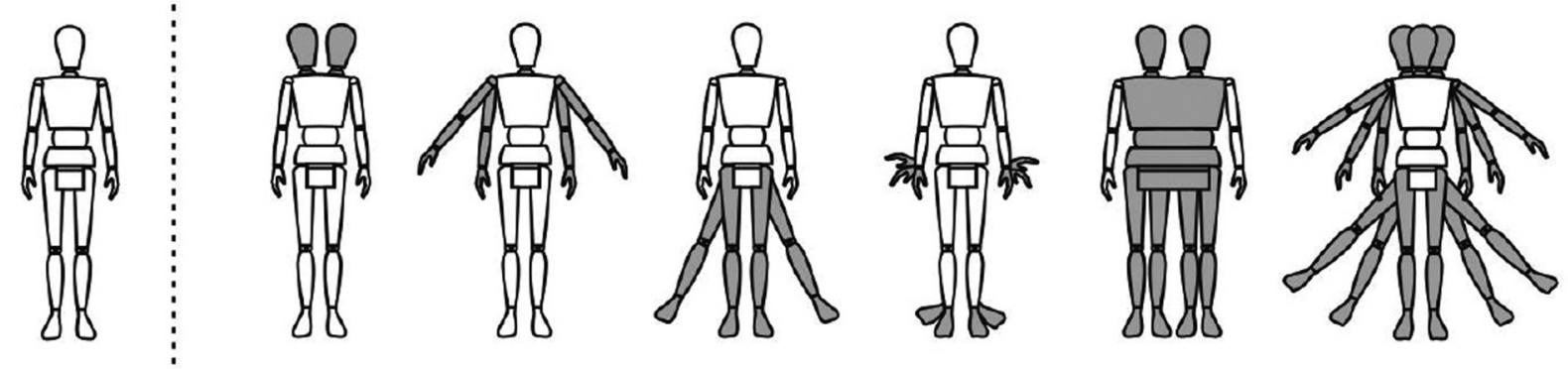

Figura $\mathbf{N}^{\mathbf{0}} 13$. Ejemplos Alteración por Multiplicación y adición

Alteración por tamaño: Donde una parte de masa del personaje se desplaza o toma parte de una extremidad de la figura cambiando su tamaño ya sea proporcionalmente o de manera libre.

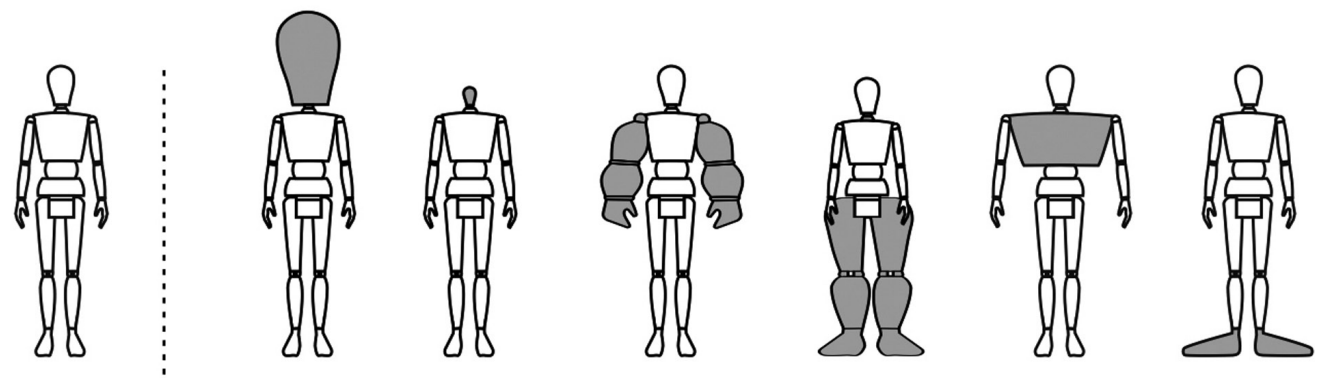

Figura $\mathrm{N}^{\mathbf{0}}$ 14. Ejemplos Alteración por Tamaño 
Alteración por posición: Las partes de la figura son desplazadas o toman otra posición en relación con su orden estructural.
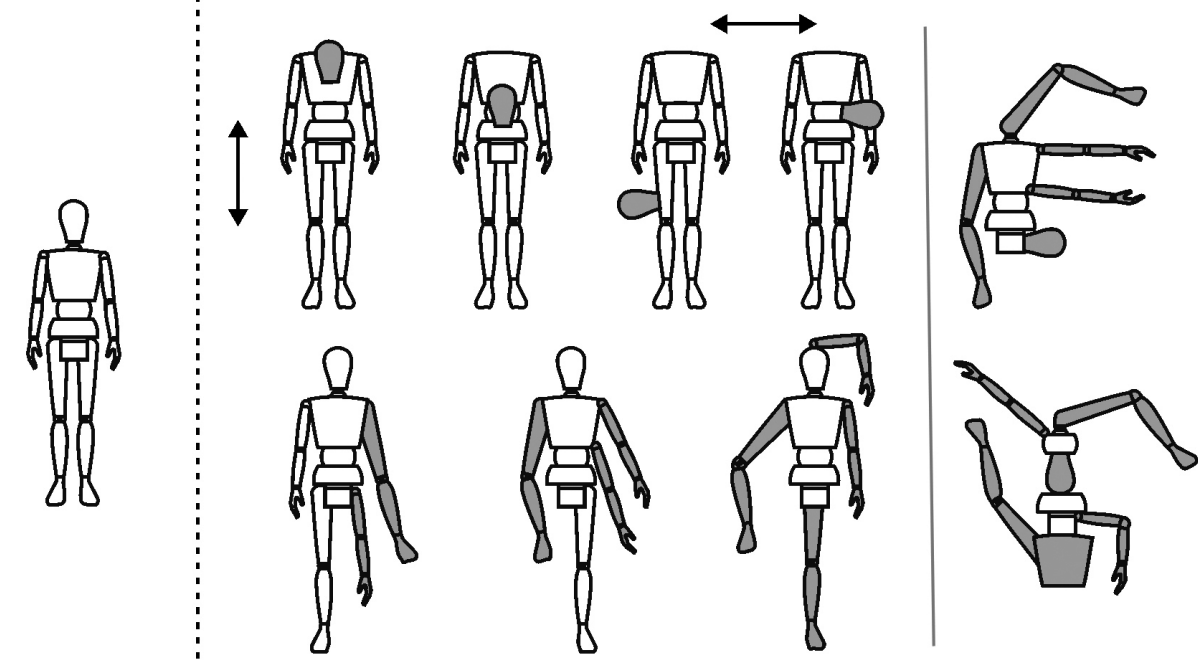

Figura $\mathbf{N}^{\circ}$ 15. Ejemplos Alteración por Posición

Alteración por separación y sustracción: Una o varias partes de la figura toman distancia o son omitidas. Se puede relacionar con las características de ubicación espacial como lo planteado por Román Gubern (1992) en las modalidades topofigurativas de la imagen, primordialmente en las relaciones de contacto y vecindad.

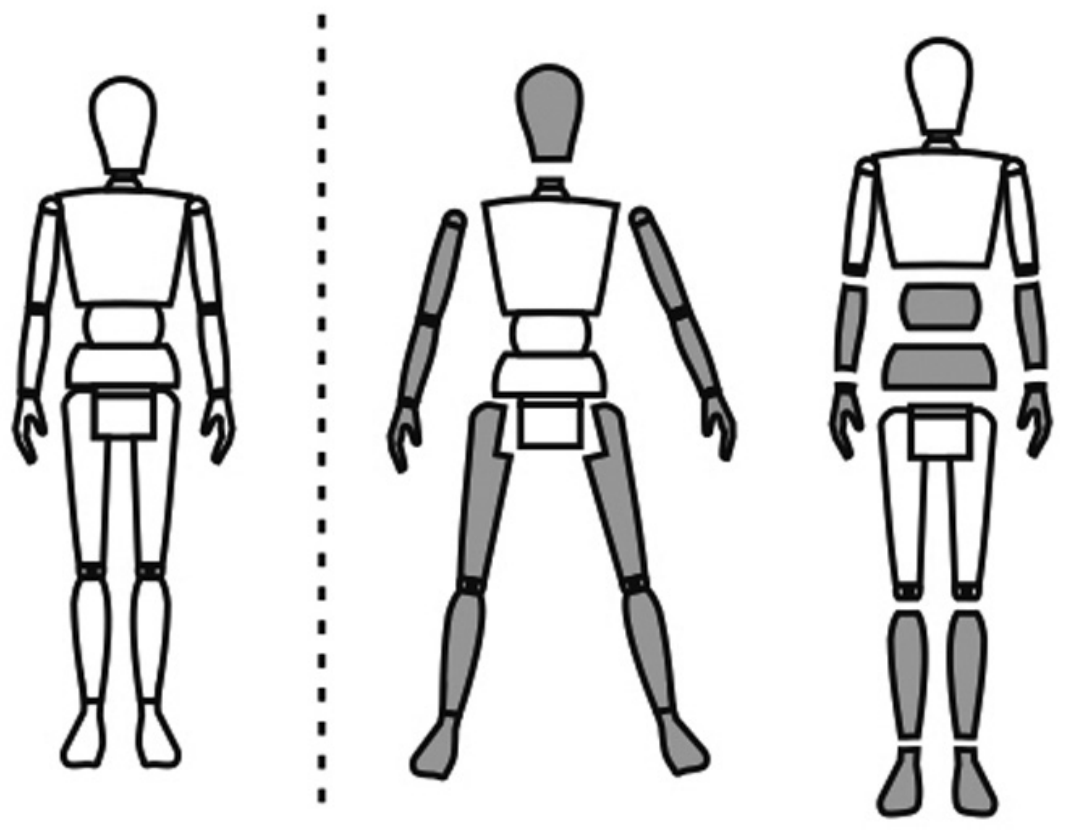

Figura $\mathbf{N}^{\mathbf{0}}$ 16. Alteración por Separación o sustracción 
Alteración por metamorfosis (morphing): Aquí la figura cambia de forma, conservando propiedades sicológicas del personaje. El cambio de estructura se da cuando una figura se transforma hasta llegar a ser otra entidad. Un ejemplo común se observa en la novela de Franz Kafka, cuando Gregorio Samsa aparece transformado en un insecto: de una estructura antropomorfa pasa a una hexápoda (seis patas), o de un queso a un ratón. Sin embargo, la metamorfosis puede ocurrir sin alterar la estructura, como en el caso del cortometraje "Betty Boop for President" (1932), en donde las entidades del rostro conservan la misma posición pero su forma sufre cambios.
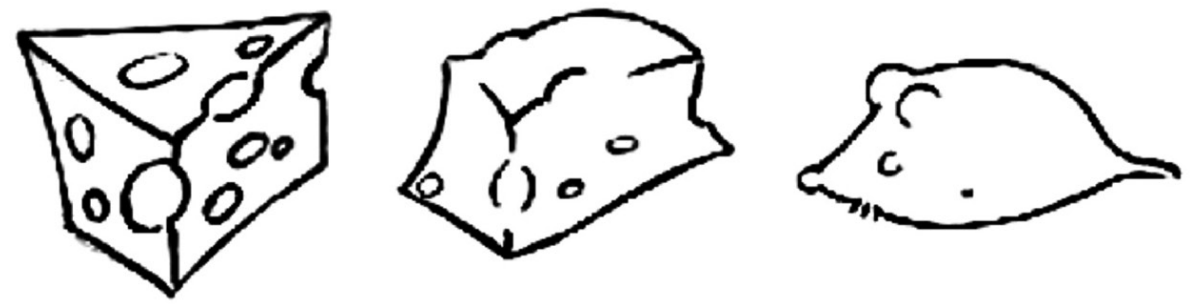

Figura $\mathbf{N}^{\mathbf{0}}$ 17. Alteración por Metamorfosis Chris Webster. Técnicas de Animación. España: Anaya, 2006.P. 36

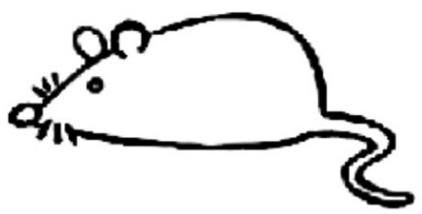

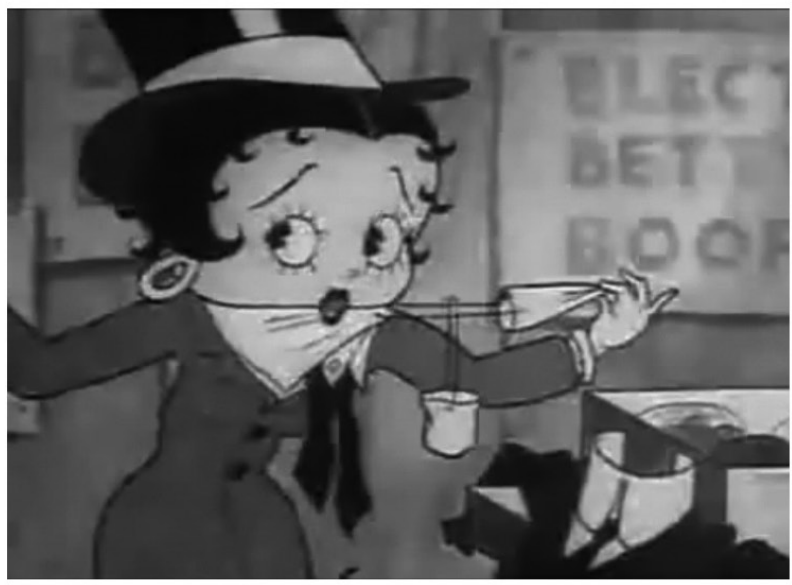

Betty Boop for president (1932)

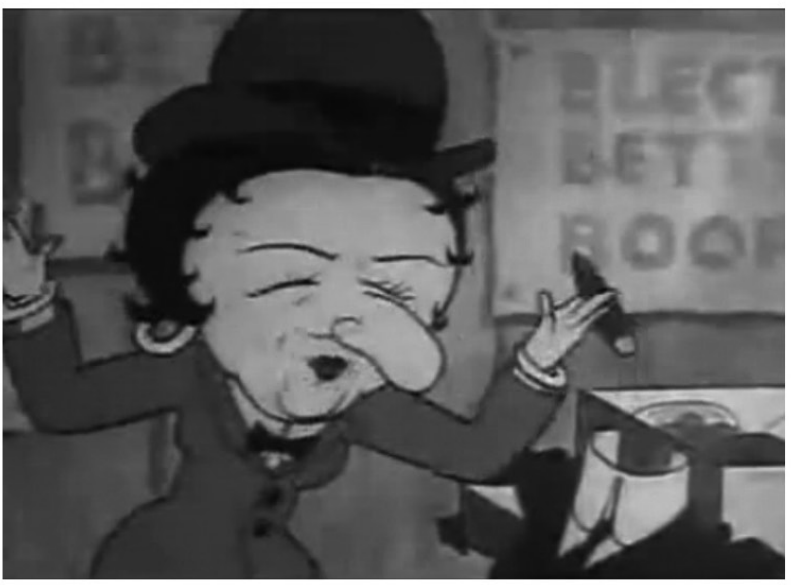

Figura $\mathrm{N}^{\mathbf{0}} \mathbf{1 8}$. Metamorfosis Betty 


\section{Conclusiones}

El recorrido de este marco conceptual ha cubierto con relativa brevedad las nociones fundamentales del dibujo animado, deteniéndose con precaución en la revisión de la imagen móvil y la relación discursiva que se ha instituido entre la imagen fija y los códigos perceptivos de la ilusión de su movilidad, para llegar finalmente a la caracterización y categorización de las alteraciones formales; tanto procedentes del concepto de transformación como del de distorsión. El concepto de distorsión se estudió cuidadosamente, precisamente porque de esta diferenciación surgen aspectos claves para dicha caracterización.

La distorsión y la deformación suelen vincular y relacionar de forma similar fenómenos variados en la percepción y representación de la imagen que utilizan elementos dinámicos como la tensión, la orientación, la proximidad, la proporción, el ritmo en conjunto con la distancia, ángulo y fisiología de la visión del observador estático o en movimiento, respecto a lo observado y de su capacidad de relacionar la imagen con un modelo figurativo y de temporalidad, en razón de su experiencia. El empleo de la distorsión en la imagen se debe principalmente al uso creciente o decreciente de tensión respecto al eje central de una figura (como la distorsión tipo barril y corsé) que puede ser asimétrico o paralelo y que está familiarizado en ocasiones con las figuras retóricas para producir efectos de mayor intensidad; pero también deja de lado otras transformaciones como la multiplicación y superposición de la imagen (como en obras futuristas y en el cómic), la ocultación parcial, en la que pareciera dividir o sustraer la figura, y la metamorfosis, donde interviene la relación entre forma y estructura.

La identificación de las alteraciones formales debe partir de la identificación inicial del personaje (en tanto recurso retórico, como la caricatura, y con base en el principio de constancia fisonómica) y continúa en la reproducción de los fotogramas, en donde se determina si existen cambios según los elementos dinámicos en relación con el desplazamiento en el espacio bidimensional. Se debe realizar, por lo tanto, la comparación del personaje estudiado en sus determinantes de imagen fija y su representación en movimiento. Esta identificación está sujeta a la fragmentación del personaje en sub-entidades que pueden ser reconocibles y se afectan en el espacio.

Finalmente, a donde se espera llegar con este estudio, en una fase posterior, es al empleo de la categorización de las alteraciones en el dibujo animado en el análisis de obras de animación completa y limitada, según las técnicas de animación y sus diferentes géneros.

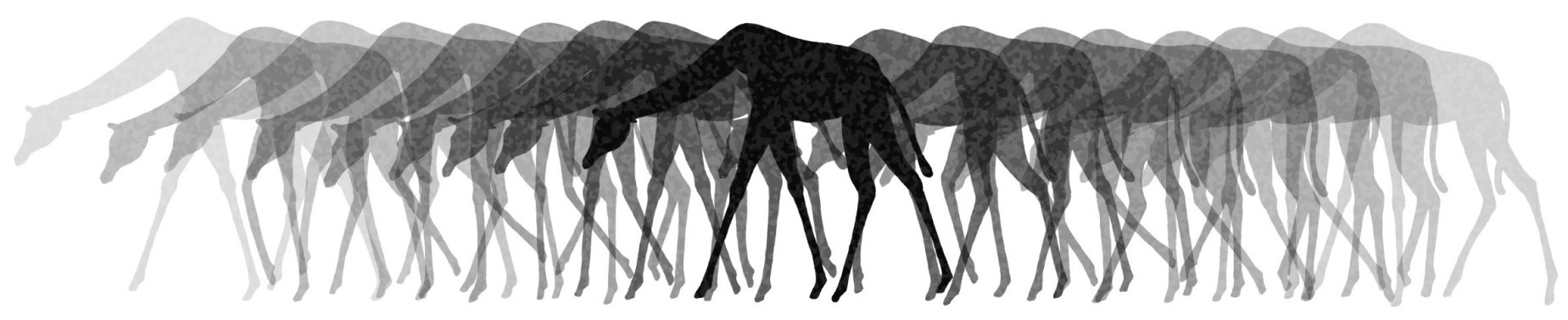




\section{Notas}

1 Proyecto presentado por Nathaly Ortiz Lugo para obtener el título de Diseñadora Gráfica en la Universidad del Valle y cuya dirección estuvo a cargo de Andrés Reina Gutiérrez.

2 También llamado compresión y extensión, se utiliza para acentuar una acción (Johnston \& Thomas, 1981), en la aplicación de este principio se pretende conservar el volumen del elemento animado mientras utiliza una direccionalidad, y que dependiendo de la intención comunicativa puede aplicarse en una parte de la figura o en su totalidad hasta alcanzar niveles exagerados.

3 Christian Metz (1972:28) explica que "lo verosímil es algo que no es lo verdadero pero que no es demasiado diferente: es lo que se parece a lo verdadero sin serlo", en el caso del dibujo animado, se destaca el factor de movimiento que permite una verosimilitud o una convención posible de movimiento en contraste con la alteración formal dada que hace parte de un imposible, debido a que el modelo de referencia no sufre cambios exagerados como en la figura animada pero sí existen trayectorias similares, teniendo así una dualidad entre la transformación no mimética de la figura en oposición al movimiento verosímil.

4 Los modos de animación están asociados con el orden de dibujo o método de realización, y se conocen como acción directa y pose a pose. Los tipos tienen que ver con el número y repetición de imágenes en un tiempo determinado, se conocen como animación total y limitada, tanto los modos como los tipos se formalizaron con el nacimiento del dibujo animado: La acción directa, se basa en orden cronológico donde los dibujos siguen una secuencia natural (fotogramas 1, 2, 3...), el movimiento adquiere mayor fluidez, es improvisado y libre; pero presenta problemas ya que el personaje animado puede cambiar de proporción o solidez. Lo contrario sucede con el método de pose a pose ya que el dibujo es realizado intercaladamente, comenzando por el inicial y el final y luego por el intermedio y así sucesivamente $(1,3,2)$, de esa forma permite que exista un control sobre las proporciones y tiempo de ejecución. Los tipos de animación pueden estar sujetos a fines estéticos o a tiempos de duración de una producción animada: animación total, donde la proporción en cantidad de dibujos es equivalente al número de fotogramas por segundo donde los valores comunes están entre 24, 29 y 30 fotogramas por segundo; animación limitada, cuyo sentido de economía puede estar sujeto al número de posiciones del personaje entre 12, 8 o 6 f/s (Castro y Rodríguez, 1999).

5 El timing es un componente fundamental aplicado a las técnicas de animación, es la distancia relativa de la posición del elemento animado que existe entre un fotograma y otro en un determinado lapso de tiempo, controla la velocidad y el ritmo. Webster (2006) clasifica lo llamado comúnmente como timing en Ritmo y Expresión: el ritmo está relacionado con el contexto total del relato, donde los acontecimientos están sujetos a la temporalidad de la narración e intervienen niveles de duración, orden y frecuencia, estas son "figuras temporales propias del acto de relatar" (Gaudreault \& Jost, 1995) y pertenecen más a la interacción de movimientos que se conectan directamente mediante el montaje; la expresión, que está relacionada con el contraste de expresiones o intereses aplicados en la figura para lograr una acción, donde el personaje según la situación puede aumentar la velocidad o disminuirla, también señala Arnheim (1996) que puede determinar factores en el personaje como por ejemplo qué personalidad posee, como se siente, cual es su relación con otro individuo y generar así, contrastes entre temperamentos; pero esa cualidad expresiva no es propia del actor, sino que también se presenta en el movimiento del ambiente, la cámara y en el ritmo del montaje (Códigos visuales de movilidad).

6 Como Rudolf Arnheim, Donis Dondis, Wong, Scott, entre otros.

7 Esto alude a la ley de cerramiento que se refiere a las zonas faltantes u ocultas donde existe tendencia de seguir una línea de lectura sugerida en el espacio que el cerebro tiende a completar (Leyes de la forma, [Gubern, 1992]).

8 (1924). Conceptos fundamentales en la Historia del Arte. Madrid: Cast.

9 Las imágenes referidas son de origen de producción técnica, Joan Costa (2003) las denomina imágenes materiales ya que corresponde a las obras pictóricas (en su mayoría ejemplificada por el Grupo $\mu$ ), la fotografía, y las imágenes desarrolladas por computador, etc. Costa define tres tipos de imágenes, las materiales anteriormente nombradas, las retinianas que son producto del sistema perceptivo, generada a través del proceso entre el ojo y el cerebro, y las imágenes mentales, que provienen del conocimiento o memoria del sujeto con relación a su experiencia; esta diferenciación es establecida ya que los signos icónicos pueden pertenecer a los diferentes campos perceptivos, como explica el grupo $\mu$ (1993:99) el signo icónico puede ser visual (perteneciente al proyecto), pero también puede ser auditivo, táctil, olfativo, etc.

\section{Referencias}

Arnheim, R. (1996). El cine como arte. Barcelona: Paidós Ibérica.

Arnheim, R. (2000). Arte y percepción visual. Psicología del ojo creador. Madrid: Alianza Editorial.

Davis, F. (1976). La comunicación no verbal. España: Alianza Editorial.

Deleuze, G. (1984). La Imagen-Movimiento, estudios sobre cine I. Barcelona: Paidós Ibérica. 
Dondis, A. D. (1976). La Sintaxis de la imagen, Introducción al alfabeto visual. Barcelona: Gustavo Gilli.

Eco, U. (1970). La definición del arte. España, Barcelona: Martínez Roca.

Gaudreault, A. \& Jost, F. (1995). El relato cinematográfico: cine y narratología. España: Paidós Ibérica.

Gombrich, E., Hochberg, J. \& Black, M. (1973). Arte, Percepción y Realidad. Conferencias en Memoria de Alvin y Fanny Blaustein Thalheimer. Barcelona: Paidós Ibérica.

Gombrich, E. H. (1982). Arte e ilusión: Estudio sobre la psicología de la representación pictórica. Barcelona: Gustavo Gili. 87 . (1993). La Imagen y el ojo, nuevos estudios sobre la psicología de la representación pictórica (2ed.). Madrid: Alianza. . (1998). Meditaciones sobre un caballo de juguete y otros ensayos sobre la teoría del arte. Madrid: Debate.

Gubern Román. (1992). La mirada Opulenta, exploración de la iconosfera contemporánea. Barcelona: Gustavo Gili.

Grupo $\mu$. (1993). Tratado del signo visual. Para una retórica de la imagen. Madrid: Cátedra.

Johnston, O. \& Thomas, F. (1981). The Illusion of Life, Disney Animation. New York: Abbeville Press.

Kepes, G. (1976). El Lenguaje de la visión. Buenos Aires: Infinito.

Malacara, D. (2004). Óptica básica (2 ed.). México: FCE.

Moliné, M. (2000). La fuerza de la publicidad. España, Madrid: McGraw Hill.

Moralejo, S. (2004). Formas Elocuentes, reflexiones sobre la teoría de la representación. España, Madrid: Akal.

Nagy, Moholy. (1947). Vision in Motion. Estados Unidos: Paul Theobald.

Panofsky, E. (2000). El significado en las ArtesVisuales. Madrid: Alianza.

Ricoeur, P. (1977). La Metáfora viva. Argentina: Megapolis.

Sánchez N. J. (2002). Historia del Cine, Teoría y géneros cinematográficos, fotografía y televisión. España, Madrid: Alianza.

Rodríguez, B. M. (2007). Animación, una perspectiva desde México. México DF: Universidad Nacional Autónoma de México, Centro universitario de estudios cinematográficos.

Todorov, T. (1971). Literatura y significación. España: Planeta Colombiana.

Villafañe, J. (2006). Introducción a la teoría de la imagen. Madrid: Pirámide.

Williams, R. (2001). The Animator's Survival Kit, a Manual of Methods, Principles and Formulas. New York: Faber \& Faber.

Webster, C. (2006). Técnicas de Animación. España: Anaya.

\section{Documentos en Línea citados}

Bishko, L. (2007). The Uses and Abuses of Cartoon Style in Animation. En Animation Studies. Valencia, (Department of Film and Video, California Institute of the Arts) Vol. 2, P.P. 24-35. Recuperado 19 Septiembre de 2009 de http:/ / www.animationstudies.org (Society for Animation Studies).

Falcone, J. (2002). De Altamira a Toy Story, Evolución de la Animación Cinematográfica. Universidad de Palermo, Facultad de Diseño y Comunicación. Argentina: Proyectos de Desarrollo. Recuperado 5 Noviembre de 2009 de <http://www.palermo.edu/dyc/publicaciones/cuadernos/pdf/cuaderno08.pdf\#page=49>

Zúñiga, R. \& Danghelly, G. (2009). Algunos problemas de análisis en las series animadas contemporáneas. Diálogos de la Comunicación: Revista académica de la federación latinoamericana de facultades de comunicación social. Colombia: Santa fe de Bogotá. Recuperado 20 de Febrero de 2010 de http: / / www.dialogosfelafacs.net/78/articulos-resultado.php?v_idcodigo $=110 \& v \_i d c l a s e=12$

\section{Filmografía}

Avery, T. (1946). Droopy: Northwest Hounded Police. Estados Unidos: MGM.

Fleischer, M. \& D. (1932). Betty boop for president. Estados Unidos: Fleischer.

Kneitel, S. (1950). How Green is my Spinach. Estados Unidos: Famous.

Plympton B. (1987). Your Face. Estados Unidos

Trousdale G.; Wise K. (1991). La Bella y la Bestia. Estados Unidos: Walt Disney. 